\title{
May the Force Be With You: The Light and Dark Sides of the Microbiota-Gut-Brain Axis in Neuropsychiatry
}

\author{
Eoin Sherwin $^{1} \cdot$ Kiran V. Sandhu ${ }^{1} \cdot$ Timothy G. Dinan ${ }^{1,2} \cdot$ John F. Cryan $^{1,3}$
}

Published online: 14 July 2016

(c) The Author(s) 2016. This article is published with open access at Springerlink.com

\begin{abstract}
The role of the gut microbiota in health and disease is becoming increasingly recognized. The microbiota-gut-brain axis is a bi-directional pathway between the brain and the gastrointestinal system. The bacterial commensals in our gut can signal to the brain through a variety of mechanisms, which are slowly being resolved. These include the vagus nerve, immune mediators and microbial metabolites, which influence central processes such as neurotransmission and behaviour. Dysregulation in the composition of the gut microbiota has been identified in several neuropsychiatric disorders, such as autism, schizophrenia and depression. Moreover, preclinical studies suggest that they may be the driving force behind the behavioural abnormalities observed in these conditions. Understanding how bacterial commensals are involved in regulating brain function may lead to novel strategies for development of microbiota-based therapies for these neuropsychiatric disorders.
\end{abstract}

John F. Cryan

j.cryan@ucc.ie

1 APC Microbiome Institute, University College Cork, Cork, Ireland

2 Department of Psychiatry and Neurobehavioural Science, University College Cork, Cork, Ireland

3 Department of Anatomy and Neuroscience, University College Cork, Western Gateway Building, Cork, Ireland

\section{Key Points}

The gut microbiota regulate central nervous system homeostasis through immune, vagal and metabolic pathways.

Dysregulation of the gut microbiota has been documented in several neuropsychiatric conditions, such as depression and autism.

Preclinical and clinical evidence suggests that psychobiotics display efficacy in alleviating the behavioural symptoms of neuropsychiatric disorders.

\section{Introduction}

"The Force is what gives a Jedi his power. It's an energy field created by all living things. It surrounds us and penetrates us." (Obi Wan Kenobi, Star Wars: Episode IV-A New Hope)

The microbiota are not unlike the mystical Force seen in the Star Wars movies. In these movies, individuals who can sense the Force are said to contain a large number of 'midi-chlorians', which are "microscopic lifeforms that live symbiotically inside the cells of all living things" (Qui Gon Jinn, Star Wars: Episode I-The Phantom Menace. Similarly, we share a symbiotic relationship with the bacterial microorganisms that live within us, with a large population residing within our gastrointestinal system. Recent advances in sequencing technology have revealed that the microbiota in our gut comprise approximately 1800 different phyla and 40,000 bacterial species [1]. The main 
bacterial phyla in the gut include the Firmicutes (such as Lactobacillus) and the Bacteroidetes (i.e. Bacteroides); other phyla include Proteobacteria, Actinobacteria (i.e. Bifidobacterium) and Cyanobacteria [2]. The gut microbiota, like the Force, give us power. These various species of bacteria interact with the rest of the body through regulation of the immune system and secretion of factors such as short-chain fatty acids (SCFAs), which influence physiological processes throughout the body. Through a bi-directional communication network with the brain, called the microbiota-gut-brain axis, the bacterial commensals help to maintain homeostasis of the central nervous system (CNS) and influence our behaviour and mood. In the Star Wars movies, Jedi knights are known for their calm, peaceful demeanour and positivity. Modulators of the microbiota, such as prebiotics and probiotics, have been shown to reduce levels of the stress hormone cortisol and improve mood in healthy volunteers, making their behaviour more 'Jedi-like' [3]. Interestingly, there is considerable evidence to suggest a role for the gut microbiota in neuropsychiatric conditions, such as depression, autism and schizophrenia, which may be the driving force behind the behavioural abnormalities observed in these disorders.

\section{Communication Between the Gut Microbiota and the Brain}

"I could show you the ways of the Force." (Kylo

Ren, Star Wars: Episode VII-The Force Awakens)

The bacterial commensals in our gut communicate with the CNS and regulate brain neurochemistry and behaviour in a number of different ways, which are slowly being resolved. These mechanisms include production of bacterial metabolites and immune mediators, such as cytokines, and signalling to the brain directly via the vagus nerve [4-6] (see Fig. 1).

\subsection{Immune Responses}

The immune system acts as an important intermediary between the gut microbiota and the brain [4]. The signalling mediators of the immune system-cytokines-can signal to the brain from the periphery via the vagus nerve, or they can access the brain directly via the circumventricular organs (regions of the blood-brain barrier [BBB] that are relatively permeable). Gram-negative bacteria can stimulate production of pro-inflammatory cytokines, such as interleukin (IL)-6 and IL-1 $\beta$, through binding of the lipopolysaccharide (LPS) component of their cell walls to toll-like receptors (TLRs; i.e. TLR-4), which are expressed upon monocytes, macrophages and microglia. In conditions such as irritable bowel syndrome (IBS) and depression, there is thought to be a breakdown in intestinal permeability, which leads to translocation of bacteria from the lumen of the gut to the systemic circulation, where they can elicit an inflammatory response by stimulating TLR-4 on circulating immune cells $[7,8]$. The inflammatory response in the gut can also signal to the brain via the vagus nerve. For instance, intestinal inflammation in mice, triggered by Campylobacter jejuni infection, was associated with increased neuronal activation (represented by c-Fos immunohistochemistry) in vagal sensory ganglia and in the nucleus of the solitary tract (the primary afferent of the vagus nerve), indicating that intestinal inflammation signals to the brain via this nerve [9]. VSL\#3-a probiotic composed of various Lactobacilli, Bifidobacteria and a Streptococcus species - attenuated both sickness behaviour and systemic inflammation induced by bile duct ligation [10]. Studies such as these demonstrate that the gut microbiota are capable of modulating the peripheral inflammatory response, which can affect brain function and behaviour.

\subsection{The Vagus Nerve}

The tenth $(\mathrm{X})$ cranial nerve-the vagus nerve-plays a crucial role in facilitating bi-directional communication between the brain and the gut microbiota [11, 12]. The vagus nerve represents the main afferent pathway from the abdominal cavity to the brain, and there is sufficient evidence to indicate that the gut microbiota are capable of activating this pathway to mediate their behavioural and physiological effects on the brain. For instance, the vagus nerve is responsible for mediating the beneficial effects of probiotics on physiological mechanisms such as wound healing [13]. Lactobacillus reuteri was shown to enhance wound healing in mice by increasing oxytocin release from the hypothalamus, which was effectively blocked following vagotomy [13]. The vagus nerve is also a crucial component in mediating how alterations in the gut microbiota impact upon behaviour. For instance, transient inactivation of the dorsal vagal complex was shown to attenuate social isolation deficits, which were induced following peripheral LPS administration [14]. Severing of the vagus nerve also facilitated anxiolytic-like behaviour in rats, which was accompanied by an attenuation in conditioned fear [15]. Furthermore, the anxiogenic behaviour induced by dextran sulfate sodium (DSS)-mediated colitis was attenuated following vagotomy, indicating that the vagus nerve is an intermediary in facilitating the detrimental behavioural effects of colonic inflammation. Vagotomy also blocked the anxiolytic effect of Bifidobacterium longum in step-down inhibitory avoidance [16]. Similarly, the anxiolytic and antidepressant-like 


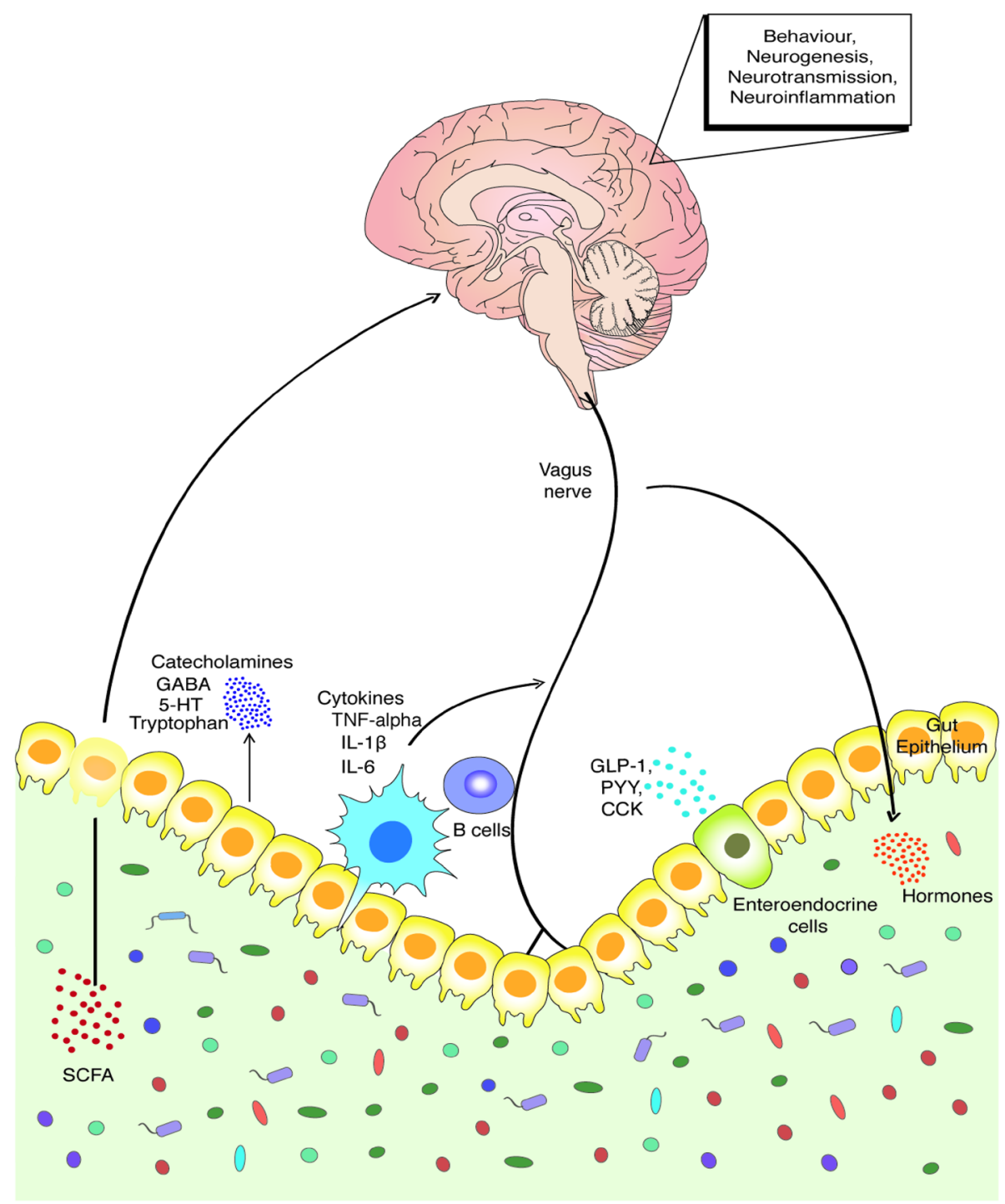

Fig. 1 Key communication pathways of the microbiota-gut-brain axis. There are numerous mechanisms through which the bacterial commensals in our gut can signal to the brain. These include activation of the vagus nerve, production of immune mediators and microbial metabolites (i.e. short-chain fatty acids [SCFAs]), and enteroendocrine cell signalling. Through these routes of communication, the microbiota-gut-brain axis controls central physiological processes, such as neurotransmission, neurogenesis, neuroinflammation and neuroendocrine signalling. Dysregulation of the gut

effects observed following Lactobacillus rhamnosus ingestion were not observed in vagotimized mice [11]. Thus, the vagus nerve is also important in mediating the beneficial behavioural effects of probiotics. However, it must be considered that the vagus nerve is not the only route through which the microbiota can influence behaviour. Bercik and colleagues [17] demonstrated that when the composition of the gut microbiota in mice was transiently altered following antimicrobial administration, the anxiolytic effect of the antimicrobial treatment was independent of the vagus nerve. This suggests that there are microbiota subsequently leads to alterations in all of these central processes. There have been numerous reports of alterations in the gut microbiota in neuropsychiatric conditions, which may account for the behavioural abnormalities that are characteristic of these conditions. Normalizing the composition of the gut microbiota with use of probiotics and prebiotics may represent a viable treatment option for neuropsychiatric conditions. 5-HT serotonin, $C C K$ cholecystokinin, $G A B A \gamma$-aminobutyric acid, GLP glucagon-like peptide, IL interleukin, $P Y Y$ peptide YY, TNF tumour necrosis factor

other biological mechanisms at play, mediating the behavioural effects of the gut microbiota.

\subsection{Short-Chain Fatty Acids}

Acetic acid, propionic acid and butyric acid are the main SCFA metabolites produced by the bacterial commensals in our gut. These SCFAs are inhibitors of histone deacetylases [18] and can also elicit intracellular signalling by binding to their cognate G-protein coupled receptors (e.g. free fatty acid receptors [FFARs]) to 
influence a range of physiological functions throughout the body [19]. These SCFAs act as an intermediary between the gut microbiota and the brain, and they represent an additional mechanism through which gut bacteria can influence brain physiology and behaviour. Microbial-derived SCFAs are capable of signalling to the brain indirectly via nerve activation to influence physiology and behaviour. Propionic acid exerts beneficial effects upon body weight control and glucose metabolism by activating the FFAR3 receptor upon nerve fibres of the portal vein [20]. On the other hand, SCFAs can affect brain physiology and behaviour directly. Evidence suggests that butyric acid and propionic acid are capable of modulating neurotransmission [21-23]. Both butyric acid and propionic acid have been shown to increase expression of tyrosine hydroxylase, the rate-limiting enzyme in dopamine and noradrenaline synthesis [23]. These SCFAs also attenuated expression of dopamine- $\beta$-hydroxylase, the enzyme responsible for converting dopamine into noradrenaline. Propionic acid also increased tryptophan hydroxylase expression, which suggests that this SCFA is also capable of modulating serotonergic neurotransmission [23]. Propionic acid has been shown to lower levels of $\gamma$-aminobutyric acid (GABA), the indoleamine serotonin (5-hydroxytryptamine; 5-HT) and dopamine in vivo [24]. These effects of SCFAs on brain physiology may help to explain their effect upon behaviour, as butyric acid has been shown to produce antidepressant-like effects in preclinical tests, while neurotoxic or excessive doses of propionic acid are associated with deficits in cognition and sociability [25-28].

SCFAs are also capable of regulating glial homeostasis. Pretreatment of primary microglial cultures with butyric acid has been reported to protect against LPS-induced inflammatory responses [29]. Moreover, long-term SCFA treatment has been reported to reverse microglial immaturity and malformation observed in germ-free mice (mice that had grown up without any exposure to microbes), which was dependent upon activation of FFAR2 [30]. However, this effect of SCFAs upon microglial homeostasis is not as straightforward as it seems, as propionic acid has been shown to promote microglial activation (represented as increased cluster of differentiation [CD] 68 expression) [27]. Thus, regulation of microglial activation by SCFAs depends upon the particular type and concentration of SCFA being applied. These opposing regulatory roles of butyric acid and propionic acid in glial cell activation also apply to astrocytes. Propionic acid has been reported to increase expression of the astrocytic marker glial fibrillary acidic protein (GFAP), while butyric acid was found to reduce its expression [31-33]. Thus, an increase in SCFA-producing bacteria in the gut may have an effect upon the neuroinflammatory response controlled by microglia and synaptic regulation mediated by astrocytes.

\subsection{Enteroendocrine Signalling}

Enteroendocrine cells (EECs) are specialized cells of the intestine, which are capable of producing peptides/signalling molecules (i.e. 5-HT, cholecystokinin [CCK], glucagon-like peptide [GLP]-1 and peptide YY [PYY]), chemosensing gut luminal contents and mediating energy homeostasis [34]. EECs are distributed along the entire length of the gastrointestinal mucosa and are suggested to represent approximately $1 \%$ of epithelial cells in the gut lumen [34, 35]. GLP-1, PYY and CCK are all released from EECs following food intake, particularly after ingestion of fats and carbohydrates. These peptides/hormones act by binding to their cognate receptors upon the vagus nerve to inhibit gastric emptying, induce satiety and reduce meal size [34]. Moreover, GLP-1 and PYY have both been shown to play a role in energy expenditure (for a review, see Bauer and colleagues [36]). Receptors for these peptides are expressed centrally in regions such as the nucleus of the solitary tract and the hypothalamus. Consequently, these gut peptides may mediate satiety and their other behavioural responses by directly binding to their cognate receptors in the brain. However, whether some of these gut peptides are capable of reaching the brain directly is unknown. GLP-1, for instance, is rapidly metabolized by dipeptidyl peptidase IV at its site of secretion, and it is unlikely to reach the CNS to activate its receptors [34]. Interestingly, there is evidence to indicate that bacterial commensals are capable of regulating enteroendocrine signalling, which is not surprising, given that these cells are directly exposed to bacterial commensals in the gut. Germfree mice display alterations in the numbers of EECs in the ileum and colon. Moreover, these animals exhibit attenuated expression of PYY, GLP-1 and CCK, which suggests that the microbiota may stimulate production of these satiety peptides [37]. Recently, it has been determined that proteins secreted from Escherichia coli are capable of stimulating release of GLP-1 and PYY from EECs [38]. One protein produced by gut Escherichia coli that may facilitate the release of GLP-1 and PYY is caseinolytic protease $\mathrm{B}(\mathrm{ClpB})$. Breton and colleagues [38] have suggested that $\mathrm{ClpB}$, being an antigen mimetic of $\alpha$-melanocyte-stimulating hormone ( $\alpha$-MSH), may increase the release of the satiety peptides by binding to melanocortin receptor 4 (MCR4) upon EECs. This is a plausible mechanism, as stimulation of MCR4 upon EECs has previously been shown to increase secretion of GLP-1 and PYY peptides [39].

SCFAs have been shown to influence secretion of satiety peptides from EECs. The microbial metabolites increase 
secretion of CCK, PYY and GLP-1 through binding to their cognate FFAR1 and FFAR3 receptors, which are also expressed upon EECs [40, 41]. Nøhr and colleagues [41] demonstrated that propionic acid and other agonists of FFAR1 and FFAR3 are capable of increasing the release of GLP-1 from colonic crypt cultures. Further support for this regulatory role of the gut microbiota has been seen with prebiotics. Oligofructose and other inulin-type fructan prebiotics promote satiety in rats, which appears to be dependent upon increasing the level of GLP-1 while also decreasing ghrelin levels in the intestine [42, 43]. This effect of oligofructose has also been observed in humans [44]. Prebiotic supplementation may promote satiety by increasing the production of certain SCFAs, which in turn modulate EECs and their secretion of hormones and peptides, such as GLP-1 and ghrelin.

\subsection{Tryptophan Metabolism}

Tryptophan is a key dietary amino acid whose metabolites, kynurenine and 5-HT, are incorporated into energy metabolism and neurotransmission, respectively. 5-HT is a fundamental neurotransmitter, which regulates physiological processes such as mood, appetite, aggression and sleep [45]. Moreover, the mechanism of action of conventional antidepressants involves enhancing levels of central 5-HT to produce a therapeutic effect, which highlights the importance of agents that augment central 5-HT [46]. Aside from the 5-HT pathway, the majority of tryptophan is metabolized into kynurenine in the liver via the enzymatic actions of tryptophan-2,3-dioxygenase (TDO) for energy production, or following an inflammatory stimulus by indoleamine-2,3-dioxygenase (IDO) [47, 48]. Evidence suggests that the gut microbiota can regulate the metabolism of tryptophan, which affects the levels of kynurenine and 5-HT that can be produced. For instance, germ-free mice have been found to have higher levels of circulating tryptophan, along with lower levels of 5-HT, than conventionally colonized mice $[49,50]$. This may be due to a reduction in colonic expression of tryptophan hydroxylase (the rate-limiting enzyme in 5-HT synthesis) [51]. Furthermore, these germ-free mice have a lower circulating kynurenine-to-tryptophan ratio than conventionally colonized mice, indicating a reduction in the amount of kynurenine being produced. This is somewhat surprising, given that germ-free mice have higher circulating tryptophan levels. However, it could be that the absence of microbiota affects expression of the kynurenine-producing enzymes (IDO and TDO). Interestingly, the increase in circulating tryptophan in germ-free mice translated into increases in the level of 5-HT and 5-HT turnover in the hippocampus. This increased circulating tryptophan and elevated hippocampal 5-HT turnover was evident in male mice but not in female mice, which may have been due to an effect of the oestrous cycle on the serotonergic system [50].

Probiotic treatment has also been shown to influence tryptophan, kynurenine and 5-HT levels. Long-term treatment of rats with Bifidobacterium infantis 35624 increased circulating tryptophan levels while reducing the kynurenine-to-tryptophan ratio, possibly through enhancement of conversion of kynurenine into kynurenic acid [52]. Moreover, rats treated with Bifidobacterium infantis had lower levels of 5-hydroxyindole acetic acid (5-HIAA) in the frontal cortex, suggesting that the probiotic altered central serotonergic transmission to some degree. In terms of regulating kynurenine synthesis, Lactobacillus in the gut may attenuate the conversion of tryptophan to kynurenine by inhibiting IDO. Lactobacillus johnsonii supplementation lowered circulating kynurenine levels in rats with concomitant increases in 5-HT being observed in the ileum and in circulation. This effect of Lactobacillus johnsonii is believed to be mediated by the ability of lactic acid bacteria to produce $\mathrm{H}_{2} \mathrm{O}_{2}$, as peroxide is capable of activating the peroxidase function of IDO, which subsequently inhibits its kynurenine-producing capabilities [53]. Increased circulating and central kynurenine metabolites have been identified in autism, schizophrenia, depression and neurodegenerative diseases, such as Alzheimer's and motor neuron disease $[48,54]$. Thus, the ability of the microbiota to regulate the kynurenine pathway represents the potential to target the microbiota in conditions with elevated kynurenine levels.

\section{Targeting the Gut Microbiota}

"The Force is a pathway to many abilities that some consider to be... unnatural." (The Emperor, Star Wars: Episode III-Revenge of the Sith)

There is substantial evidence indicating that the gut microbiota play a role in various metabolic, gastrointestinal, neurological and psychiatric disorders. Consequently, understanding how the microbiota can be targeted may lead to development of microbiota-based therapies for these various conditions.

\subsection{Prebiotics}

Prebiotics refer to non-digestible fibres that are selectively metabolized by the intestinal tract and promote the proliferation of beneficial Lactobacillus and Bifidobacterium [55]. The main prebiotics include fructans (fructooligosaccharides [FOS], inulins, oligofructose) and glucans (galacto-oligosaccharides [GOS]). These prebiotics serve 
to enhance the levels of beneficial Bifidobacterium (bifidogenic properties) in the gut. For instance, B-GOS-a novel prebiotic produced from galactosidases derived from Bifidobacterium bifidum - was found to have a substantial bifidogenic effect in young healthy volunteers [56]. Fructans derived from agave plants also increased the levels of Bifidobacterium and Lactobacillus in faecal samples from healthy human participants [57]. These prebiotics are also effective in the elderly. B-GOS and FOS increased the levels of Bifidobacterium and Bacteroides in the faeces of elderly individuals $[58,59]$. Given the reported decreases in levels of Bifidobacterium in the gut with age [60], prebiotic supplementation may help to maintain healthy gut microbiota in elderly individuals and mitigate the risks of age-related gastrointestinal and psychiatric diseases. Additionally, both GOS and FOS increase production of SCFAs, presumably as a consequence of modulating the population of the gut bacterial commensals [58, 61]. Prebiotics (oligofructose) have also been shown to improve gastrointestinal homeostasis by reducing intestinal permeability and improving tight junction integrity, which may be beneficial for treating gastrointestinal disorders where barrier function is compromised [62].

\subsection{Probiotics}

Probiotics are defined as living microorganisms that confer health benefits to the host when administered [63]. In order for a microbe to be classified as a probiotic, it must meet certain criteria. First, the production process for the probiotic for administration to animals/humans must remain constant, in that there must be no variation in colonyforming units of the probiotic from one batch to the next. Second, the bacteria must survive the physiological stresses that are associated with its transport to the colon. These include the host's $\mathrm{pH}$, stomach acid production and exposure to biliary salts. Finally, the probiotic must confer a beneficial effect on the host without causing any adverse side effects [63]. The main bacterial genera used as probiotics in both animal and human studies are the Lactobacillus and Bifidobacterium genera [16, 63-65]. These probiotics enhance the composition and diversity of the gut microbiota. For instance, a probiotic mixture composed of Lactobacillus rhamnosus and Lactobacillus helveticus increased the level of Bacteroides and Firmicutes in immunodeficient mice [66]. These probiotics have multiple beneficial effects upon host physiology. For instance, Lactobacillus acidophilus enhances intestinal barrier tightness by up-regulating expression of the tight junction protein, occludin [67]. The ability of probiotics to reduce intestinal permeability represents the potential to block the bacterial translocation that occurs in conditions such as IBS, depression and autism. Other beneficial effects of probiotics include enhanced wound healing. Lactobacillus reuteri enhances wound healing by increasing secretion of oxytocin, which in turn activates $\mathrm{T}$ regulatory cells to promote healing [13]. Probiotic supplementation has also been shown to reverse age-related deficits in long-term potentiation, which suggests that they may be a useful intervention in attenuating memory deficits in the elderly [68]. When considering the beneficial behavioural effects of probiotics, it must be noted whether the bacterial strain being administered is responsible for these effects directly or by an indirect mechanism through alteration of the composition of the microbiota. Bacteria have evolved mechanisms of communication (i.e. quorum sensing), such that one bacterial species may suppress the growth of another in the gut [69]. A probiotic may suppress or enhance the growth of other bacterial species in the gut, leading to global changes in the composition of the microbiota. Thus, the behavioural effects of probiotics may arise through alteration of the composition of the microbiota. A concern regarding use of probiotics as a potential treatment is their mechanism of action. Probiotics do not have as definitive a mechanism of action as an antidepressant, for example, and are likely to exert their known beneficial effects through numerous pathways, some of which might still be unknown. Furthermore, the mechanism of action or efficacy of probiotics may vary from one individual to another because of variations in the composition of the gut microbiota from person to person. Nonetheless, there are considerable data to suggest that probiotics exert a beneficial effect upon host health and could potentially be used to treat neuropsychiatric disorders $[63,65,70]$.

\subsection{Antibiotics}

Antibiotics are our first line of pharmacological defence against bacterial infections. Although they target pathogenic bacteria, consuming antibiotics is also detrimental to the indigenous flora in our gut. Antibiotic treatment (vancomycin and imipenem) has been shown to decrease the microbial load and to reduce microbial diversity in rats. This reduction was attributed to losses in the operational taxonomic units of the two major gut phyla: Bacteroidetes and Firmicutes [71]. The reduction in microbial diversity was maintained for 3 months following cessation of an acute antibiotic treatment regime, indicating that even a brief exposure to antibiotics is sufficient to induce longlasting alterations in the gut microbiota [71]. This effect of antibiotics upon gut flora is also observed in humans, albeit with some minor differences in the response of the microbiota to these drugs. The broad-spectrum fluoroquinolone and $\beta$-lactam antibiotics increased the microbial load with a concomitant reduction in microbial diversity, 
while also increasing the Bacteroidetes-to-Firmicutes ratio in faecal samples from patients receiving a 7-day course of the medication [72]. At the species level, this study showed that antibiotics increased the proportion of several unknown taxa belonging to the Gram-negative Bacteroides genus, while also reducing taxa belonging to the Firmicutes phyla [72]. Recently, Korpela and colleagues [73] showed that a course of macrolide antibiotics was capable of inducing long-lasting alterations in the composition of the microbiota in children, which was associated with development of obesity and asthma. Interestingly, penicillin did not have as profound an effect upon the composition of the microbiota as macrolides did in that study, which suggests that the effect of antibiotics upon the bacterial composition of the gut may depend upon the class of drug being prescribed. However, Cox and colleagues [74] demonstrated in mice that penicillin is also capable of inducing longlasting metabolic changes when administered at birth. Consequently, these studies indicate that even short-term use of antibiotics in early life or in adulthood is capable of inducing long-lasting changes in the gut microbiota, which (particularly with early life use) may predispose patients to metabolic and immunological abnormalities.

Given that antibiotics alter the composition of the gut microbiota, these drugs will most like have some effect upon the microbiota-gut-brain axis. In a recent study by Tochitani and colleagues [75], male mice whose mothers had consumed a cocktail of antibiotics during pregnancy displayed deficits in locomotor activity and weighed less. However, use of normal mice to foster pups born from antibiotic-treated mothers corrected this loss of weight. Thus, it is likely that the effect of maternal antibiotic administration upon offspring weight and locomotor activity is a consequence of the poor nutritional state of the mothers following alteration of their microbiota with antibiotics, rather than a direct effect of antibiotics upon neurodevelopment. Work from our laboratory has shown that neonatal vancomycin administration to rats induced dysregulation in the gut microbiota, which persisted into adulthood, along with increasing visceral sensitivity. This antibiotic-induced increase in visceral sensitivity was independent of any effect upon depressive or anxiety-related behaviour [76]. However, some studies have shown that antibiotic-mediated alterations in the gut microbiota are associated with anxiolysis and cognitive deficits, along with reductions in hippocampal brain-derived neurotrophic factor (BDNF) [77]. This is in accordance with work from Bercik and colleagues [17], who demonstrated that an antimicrobial cocktail produced anxiolytic effects in mice. However, this was associated with an increase in hippocampal BDNF. This may have been due to the differences in the antibiotic cocktails used in both studies and in the different strains of mice used. Nonetheless, antibiotic- mediated dysregulation of the microbiota-gut-brain axis can be reversed following treatment with probiotics, as Lactobacillus paracasei has been shown to attenuate antibiotic-mediated increases in visceral sensitivity [78]. This is presumably due to restoration of the gut microbial community following probiotic intake.

\section{Impact of the Gut Microbiota on Central Nervous System Homeostasis}

"Don't underestimate the Force." (Darth Vader, Star

Wars: Episode IV-A New Hope)

Germ-free studies in mice have provided considerable insight into how the gut microbiota affect CNS homeostasis [79]. Several studies have documented that the bacterial commensals regulate neurotransmission, neurogenesis, the inflammatory status of the brain and activation of the hypothalamic-pituitary-adrenal (HPA) axis. This role of the microbiota is quite interesting when we consider that all of the aforementioned neurophysiological processes are affected in neuropsychiatric conditions.

\subsection{Neurotransmission}

\subsection{1 $\gamma$-Aminobutyric Acid}

GABA is the main inhibitory neurotransmitter in the CNS, and dysfunctions in this transmitter system are linked to mood disorders, such as depression, anxiety and autism [80]. Interestingly, the bacterial commensals in our gutspecifically, lactic acid-producing bacteria-produce this inhibitory amino acid. For instance, Lactobacillus brevis and Bifidobacterium dentium derived from the human intestine have been shown to be efficient producers of GABA derived from monosodium glutamate [81]. These bacteria produce GABA in a manner similar to the way in which it is synthesized in the CNS, through irreversible alpha-decarboxylation of L-glutamate to GABA via the enzymatic actions of glutamic acid decarboxylase (GAD) $[82,83]$. How GABA derived from the gut microbiota affects GABAergic neurotransmission has not been fully elucidated. It remains a matter of debate whether this peripherally derived GABA is capable of crossing the BBB either through diffusion or through active transport [84]. However, Takanaga and colleagues [85] provided evidence for expression of a GABA transporter at the BBB. Subsequently, GABA may be able to enter the CNS via this transporter, and this may represent a means as to how the bacterial commensals regulate central GABAergic transmission. In support of this, spectroscopic analysis of cerebral metabolites revealed that Lactobacillus rhamnosus 
(JB-1) increased the central level of GABA in mice [86]. Additionally, it appears that the gut microbiota can indirectly regulate GABAergic neurotransmission via the vagus nerve. The anxiolytic and antidepressant-like effects of Lactobacillus rhamnosus (JB-1) supplementation were associated with an increase in expression of the $\alpha 2$ subunit of the $\mathrm{GABA}_{\mathrm{A}}$ receptor, along with a concomitant reduction in expression of the $\alpha 1$ subunit of the $\mathrm{GABA}_{\mathrm{A}}$ receptor in the hippocampus, which was dependent upon the integrity of the vagus nerve [11]. Thus, it would appear that the beneficial behavioural effects of Lactobacillus involve modulation of the GABAergic transmitter system.

\subsubsection{Catecholamines: Dopamine and Noradrenaline}

Noradrenaline and dopamine are two crucial neurotransmitters in the mammalian brain. These two chemicals control complex physiological processes, such as motivation and reward, awareness, motor control and regulation of the endocrine axes. Dysfunction of these two transmitter systems has been linked to various neurological and psychiatric disorders, such as Parkinson's disease and depression. While these two catecholamines act as neurotransmitters in the CNS, they are also produced by the gut microbiota. Germ-free mice display substantially lower levels of noradrenaline and dopamine in the lumen of the caecum than specific-pathogen-free mice, which suggests that the gut microbiota are a potential source of catecholamines [87]. In support of this, some species of bacteria express transcripts with a similar sequence to tyrosine hydroxylase, the rate-limiting enzyme in noradrenaline and dopamine synthesis [88]. In terms of what strain of bacteria of the microbiota produce catecholamines, lactic acidproducing bacteria are known to synthesize dopamine in culture [89]. However, it is unlikely that these microbeproduced catecholamines have any effect upon their corresponding central metabolites, as peripherally synthesized dopamine is unable to cross the BBB. Nonetheless, the microbiota also appear to be able to modulate central catecholaminergic neurotransmission. Analysis of cerebral metabolites from germ-free mice revealed lower levels of the amino acid tyrosine-the rate-limiting substrate for noradrenaline and dopamine synthesis-in comparison with ex-germ-free controls. This corresponded with a greater level of dopamine in the brains of germ-free mice, suggesting that the absence of microbiota increased the levels of catecholamines in the brain [90]. Nishino and colleagues [91] also noted increased levels of noradrenaline and dopamine in the brains of germ-free mice relative to ex-germ-free controls. However, replenishment of the animals with microbiota increased dopamine and noradrenaline turnover in the prefrontal cortex and hippocampus of ex-germ-free mice, demonstrating that the microbiota exert a regulatory effect upon catecholaminergic transmission in the brain.

\subsubsection{Histamine}

Histamine is produced from the dietary amino acid histidine through the enzymatic actions of histidine decarboxylase. While histamine has potent immunoregulatory properties, it also acts as a neurotransmitter and is linked to central processes such as circadian rhythms, food intake, learning and pain perception [92]. Evidence suggests that the microbiota are capable of synthesizing this molecule in the gut, which may have an impact upon its availability in the brain. For instance, the probiotic Lactobacillus reuteri expresses the genes for histidine decarboxylase, indicating that it is a proficient synthesizer of histamine. Supplementation of Lactobacillus reuteri cultures with histidine has been shown to increase histidine decarboxylase expression, as well as production of histamine [93]. Interestingly, Lactobacillus reuteri inhibited production of the pro-inflammatory cytokine tumour necrosis factor (TNF)- $\alpha$ in myeloid progenitor cells through production of histamine [93]. This inhibitory effect of Lactobacillus reuteri upon TNF- $\alpha$ production appears to be dependent upon activation of the $\mathrm{H}_{2}$ histamine receptor and, subsequently, activation of the MEK/ERK mitogen-activated protein kinase (MAPK) signalling pathway. This immunomodulatory role of histamine may help to explain why histamine is required for controlling infection in the enteric nervous system [94]. Furthermore, blockade of $\mathrm{H}_{2}$ receptors has been shown to reduce mucus production and lead to an increase in gut barrier dysfunction [95]. Thus, alterations in histaminergic signalling in the gut may contribute to translocation of bacteria from the lumen into the systemic circulation, which is thought to occur in conditions such as IBS, depression and autism. Diet may also influence histamine production through modulation of the gut microbiota. IBS patients fed a diet composed of low-fermentable oligosaccharides, disaccharides, monosaccharides and polyols (FODMAP) reported an improvement in their IBS symptom severity score, which corresponded with an increase in Actinobacteria richness, as well as a decrease in urinary histamine levels [96]. This association between diet and histamine levels is potentially quite important for the treatment of IBS, given that elevated levels of histamine have been documented in patients with this gastrointestinal condition [97]. While the microbiota have been shown to influence local histamine production in the gut and in the circulation, more work is required to determine whether they can influence central histaminergic transmission. 


\subsection{Microbiota Regulation of Neurotrophic Factors}

Interestingly, research now strongly suggests that expression of BDNF is under the influence of the gut microbiota. Long-term antibiotic administration in adolescent mice results in depletion of the gut microbiota, along with a concomitant reduction in hippocampal BDNF messenger RNA (mRNA) expression [77]. Similarly, male mice raised in a germ-free environment and devoid of gut microbiota also display reduced BDNF expression, as well as altered neuronal morphology in the hippocampus, relative to conventionally colonized control mice [50, 98]. However, Neufeld and colleagues [99] noted increased BDNF levels in the hippocampus of female germ-free mice. Given that there are differences in serotonergic transmission, as well as in BDNF expression, between male and female germfree mice, it suggests that the microbiota-gut-brain axis is regulated in a sexually dimorphic manner.

Supplementation with either prebiotics or probiotics enhances the levels of the neurotrophin in the brain. Longterm administration of the prebiotics FOS and GOS to rats increased expression of BDNF mRNA within the dentate gyrus [100]. Both GOS and FOS increased Bifidobacterium levels in faecal pellets, and this bacterial species has previously been associated with an increase in hippocampal BDNF [101], so this may be one potential mechanism through which prebiotics increase expression of the neurotrophin. Studies assessing the effect of probiotic supplementation on hippocampal BDNF suggest that probiotics also promote expression of the neurotrophin under conditions of chronic stress, inflammation and aging. Bifidobacterium longum NCC3001 prevented reductions in hippocampal BDNF following chronic immune activation with the parasite Trichuris muris [101]. Furthermore, Lactobacillus helveticus NS8 reversed chronic stress-induced reductions in BDNF [102]. While it is unknown how the gut microbiota directly influence central BDNF expression, this modulatory role of the microbiota lends credence to use of probiotics for the treatment of mood disorders such as depression, which is associated with dysfunctional immune activation, chronic psychological stress and a reduction in expression of the neurotrophic factor. The probiotic VSL\#3 increased hippocampal BDNF in both young and aged mice while also improving longterm potentiation in aged animals [68]. These are promising data, as they suggest that probiotics may be useful in attenuating age-related memory deficits. Thus, probiotic supplementation in the elderly may help to protect against age-related cognitive decline and Alzheimer's disease.

In addition to regulation of expression of BDNF, the evidence also suggests that the gut microbiota are capable of influencing expression of other neurotrophic factors such as glial-derived neurotrophic factor (GDNF) and nerve growth factor (NGF). For instance, expression of NGF in the colon was attenuated following treatment of mice with antibiotics, which was associated with a reduction in visceral pain responses [103]. One way in which the bacterial commensals in the gut may promote intestinal expression of neurotrophins is through microbial signalling via TLRs, as Brun and colleagues [104] demonstrated that the TLR-2 agonist Pam3CSK4 induced expression of NGF, BDNF and GDNF in ileal smooth muscles cells. This ability of the gut microbiota to regulate neurotrophin expression within the gut is likely to have an effect upon neurotransmission within the enteric nervous system, and this warrants further investigation.

\subsection{Microbiota Regulation of Microglial Activation}

The brain's resident immune cells-the microglia-are also found to be under the regulation of the microbiota $[105,106]$. Consequently, the bacterial commensals in our gut have the potential to control the neuroinflammatory response that is often found to be exaggerated in psychiatric and neurodegenerative conditions [107, 108]. Early work with the tetracycline-derived antibiotic minocycline demonstrated that this antimicrobial compound was capable of inhibiting the activation and proliferation of microglia. Although its actions are thought to be due to its ability to stabilize microglia, a potential regulatory role of the gut microbiota in the neuroimmune response must now be also considered [109]. In light of this, when mice are raised germ free, they are found to have an increased number of IBA+ microglia in the cortex and hippocampus. These microglia display an immature phenotype, as they lack markers of maturity-such as CD44, CD62L and major histocompatibility complex (MHC) class II-while also failing to display an activated phenotype following LPS administration [30]. This effect upon microglial morphology and activation has also been observed following antibiotic treatment, which confirms that the absence or depletion of the microbiota has a profound effect upon the neuroinflammatory response [30]. The regulatory effect of the microbiota upon the neuroinflammatory status of the brain also appears to be dependent upon diet. Transplantation of gut microbiota from high fat diet-fed mice to host mice resulted in increased protein expression of the microglial markers IBA-1, TLR-2 and TLR-4, indicative of microglial activation and neuroinflammation [110]. Transplantation of high fat diet-modulated microbiota also decreased the central expression of a tight junction protein, zona occludens (ZO)-1, which may have facilitated the entry of peripheral inflammagens (i.e. LPS) into the brain and caused the observed microglial activation and neuroinflammation [110]. This relationship between the gut microbiota and the brain highlights the 
importance of an appropriate diet and the detrimental effect that obesity can have on the brain. The regulatory role of the microbiota in the neuroinflammatory response may be partly mediated by SCFAs, as neurotoxic levels of propionic acid have been shown to increase microglial activation [27], although butyric acid attenuates microglial activation following LPS administration [29]. An increase in SCFAproducing bacteria in the gut as a consequence of diet, medication or infection may lead to increased levels of the microbial metabolites in the brain, which in turn could affect microglial activation.

The commensals in our gut also regulate the neuroinflammatory process in certain neurodegenerative conditions, such as multiple sclerosis. Recent work from our group has shown that the microbiota influence myelination in the prefrontal cortex, which may have implications for conditions such as multiple sclerosis, where there is a loss of myelin [111]. Polysaccharide A (PSA) secreted from Bacteroides fragilis was protective against demyelination in a murine experimental autoimmune encephalomyelitis (EAE) model of multiple sclerosis by increasing the conversion of $\mathrm{T}$ helper $2\left(\mathrm{~T}_{\mathrm{h}} 2\right)$ cells into IL-10 producing FoxP3 $+\mathrm{T}$ regulatory cells in cervical lymph nodes $[112,113]$. Moreover, a probiotic mixture of various Lactobacillus species attenuated the behavioural and histological deficits of EAE by lowering circulating proinflammatory cytokines, such as interferon (IFN)- $\Upsilon$ and IL17. While the mechanism behind the beneficial effect of this Lactobacillus probiotic mixture in reducing EAE severity is unknown, it appears to be dependent upon synthesis of IL-10, as knockout of the gene for this antiinflammatory cytokine blocked the therapeutic effect of the probiotic [114]. This suggests that the microbiota could be targeted as a potential prophylactic or treatment for multiple sclerosis and other neurodegenerative conditions.

\subsection{Microbiota Regulation of Endocrine and Hormonal Control}

The HPA axis is the neuroendocrine system that governs the physiological stress response of mammals. Exposure to psychological or physical stressors results in activation of the paraventricular nucleus of the hypothalamus, which then stimulates secretion of corticotrophin-releasing factor (CRF) from the median eminence. CRF is transported to the anterior lobe of the pituitary via the hypophyseal portal vein, where it stimulates secretion of adrenocorticotrophic hormone (ACTH) into the general circulation. ACTH acts on the adrenal cortex to induce release of glucocorticoids, such as cortisol (humans)/corticosterone (rats/mice). Glucocorticoids regulate several important physiological processes, such as metabolism, immunity, adiposity and even neurogenesis [115]. Consequently, excessive production of these stress hormones has adverse effects on health. Several studies have documented that when mice and rats are raised germ free, these animals have elevated levels of circulating ACTH and corticosterone following exposure to stress [50, 99, 116, 117]. Moreover, expression of the glucocorticoid receptor was found to be lower in the hippocampus of germ-free mice relative to specific-pathogenfree mice. Given that the glucocorticoid receptor is a glucocorticoid-inducible gene, this down-regulation in its expression may be an adaptive response to excessive levels of circulating corticosterone [117]. Furthermore, when germ-free mice are reconstituted with microbiota, the enhanced HPA axis response to stress is partly reversed. However, this appears to be dependent upon the age of the animal, as it was effective in young mice but not in adult mice [118]. Thus, there is a critical period in development during which the microbiota can modulate stress-induced activation of the HPA axis.

Probiotics have been shown to modulate activation of the HPA axis, which may relate to their beneficial effects upon behaviour. Interestingly, this effect of probiotic supplementation upon corticosterone levels appears to be bacterial strain specific. For instance, Lactobacillus salivarius and Lactobacillus farciminis have both been shown to decrease stress-induced corticosterone secretion [119, 120]. However, Bifidobacterium has not been found to curtail levels of the stress hormone despite its beneficial behavioural effects [52, 65]. This would suggest that different probiotic strains possess distinct mechanisms of action in producing their beneficial behavioural effects. The data regarding the effects of prebiotics upon HPA axis activation are quite limited at the moment. The prebiotics 3 'sialyllactose and 6'sialylactose were found to have no effect upon circulating corticosterone following social disruption stress in mice, despite producing an anxiolytic effect [121]. However, the prebiotic B-GOS has been shown to reduce the cortisol awakening response in humans, so there is some evidence to suggest that prebiotics are capable of modulating the levels of the stress hormone [3]. Further work is required to determine the mechanism underlying how the microbiota regulate activation of the HPA axis.

Although the data are limited at the moment, the evidence suggests that other hormones are also under the control of the microbiota. For instance, recent work from our laboratory has shown that expression of vasopressin and oxytocin in the hypothalamus of mice is reduced following treatment with antibiotics [77]. This suggests that the microbiota either directly or indirectly regulate the expression of these peptide hormones. Work from Erdman and colleagues [13] would suggest the latter, as they showed that Lactobacillus reuteri enhanced wound healing through increased oxytocin release from the hypothalamus. 
This effect of Lactobacillus reuteri was dependent upon the integrity of the vagus nerve, as deafferentation of the nerve blocked this effect of the probiotic. Recently, it was shown that Lactobacillus reuteri ameliorated social deficits in murine offspring of high fat diet-fed mothers, which was associated with an increase in oxytocin immunoreactivity within the paraventricular nucleus of the hypothalamus [122]. Such promising data would suggest that there are certain species of gut bacteria that can modulate central oxytocin levels.

It is interesting to speculate whether the microbiota influences maternal behaviour, which is associated with secretion of oxytocin. Tochitani and colleagues [75] demonstrated that when female mice were administered antibiotics throughout pregnancy, their offspring displayed a mildly anxious phenotype. Interestingly, when pups born from antibiotic-treated mothers were then fostered by nonantibiotic-treated females, this behavioural phenotype was ameliorated, demonstrating that depletion of the gut microbiota affects maternal behaviour. Whether this involves oxytocin is unknown, and other mechanisms are likely at play, such as the effect of the antibiotic upon the level of prebiotics/bacteria that are transferred to the offspring via the maternal milk. Nonetheless, it is an interesting observation that the microbiota regulate maternal behaviour. Given that gut microbes have recently been shown to play a role in mediating social behaviour [77], and that deficits in the social hormone oxytocin have been documented in autism [123], further work is required to decipher microbiota-peptide interactions in neurodevelopmental disorders [124].

\section{The Gut-Microbiota-Brain Axis in Psychiatric and Neurodevelopmental Disorders}

\author{
"There is a great disturbance in the Force." (The \\ Emperor, Star Wars: Episode V-The Empire Strikes \\ Back)
}

\subsection{Depression}

Major depression is a stress-related mood disorder, characterized psychologically by low mood, feelings of worthlessness and suicidal ideation, and physiologically by alterations in the HPA axis and the immune system, as well as psychosomatic symptoms. As mentioned above, the gut microbiota are capable of regulating activation of the HPA axis and the immune system, and so it is interesting to speculate as to whether the microbiota contribute towards depression by affecting these two physiological systems. Currently, there is little clinical evidence to suggest that alterations in the gut microbiota occur in depression.
Although Naseribafrouei and colleagues [125] failed to identify any differences in terms of microbial diversity between depressed patients and controls, the levels of Bacteroidetes were found to be lower in depressed patients. However, in a recent study by Jiang and colleagues [126], pyrosequencing of faecal samples from depressed patients and healthy controls revealed increased diversity (using the Shannon index) in the composition of the microbiota in depressed patients. Of note, there was an increase in the Bacteroidetes and Proteobacteria (which include the LPSexpressing Enterobacteriaceae) phyla, with a concomitant reduction observed in the numbers of Firmicutes. The conflicting reports of microbial diversity in faecal samples between these two studies may stem from the fact that Naseribafrouei and colleagues used outpatients from a neurological unit as controls, while Jiang and colleagues used healthy subjects. Additional evidence of dysregulated microbiota in depression comes from Maes and colleagues [127], who demonstrated that a cohort of chronically depressed patients displayed increased circulating levels of immunoglobulin (Ig) A and IgM antibodies raised against LPS expressed upon Gram-negative Enterobacteriaceae. This would suggest that there is bacterial translocation from the gut to the systemic circulation during chronic depression, which would presumably lead to an inflammatory response that may be contributing towards the mood disorder.

Animal models of depression have allowed us to better understand how the gut microbiota may influence depression-like behaviours. Maternal separation is frequently used as a model of early life stress that provokes a depressive and anxiety-like phenotype, along with alterations in monoamine turnover, immune function and HPA axis activation [128-131]. Furthermore, there is considerable evidence that this model of early life stress also affects the composition of the gut microbiota. Early work from Bailey and Coe [132] demonstrated that maternal separation decreased faecal Lactobacillus in rhesus monkeys 3 days post-separation. Previous work from our laboratory has also demonstrated the adverse effects of maternal separation upon the microbiota-gut-brain axis in rats in terms of increased colonic visceral sensitivity and disruption to the microbiota themselves. While it was not determined which species of bacteria in the microbiota were affected by maternal separation, this study demonstrated that early life stress has a profound effect upon the gut commensals $[128,130]$. Recent findings by De Palma and colleagues [131] have elaborated upon the role of the bacterial commensals in the gut in the development of behavioural despair in the maternal separation model. In their study, maternal separation increased circulating corticosterone in germ-free mice independently of depressive or anxiety behaviour. This suggests that the microbiota are 
not necessarily required for stress-induced alterations in HPA axis activity but are required for development of anxiety and depression-like behaviours.

Other models of chronic stress/depression have also been shown to induce alterations in the microbiota. Olfactory bulbectomy is a rodent model of depression that displays altered neuroendocrine and neuroimmune responses and a behavioural phenotype that is similar to what is observed in clinical depression. The model also has strong predictive validity, as it responds only to long-term antidepressant treatment [133]. Interestingly, Park and colleagues [134] demonstrated that bulbectomy affects gut transit and the composition of the microbiota by redistributing the relative abundances of bacterial phyla. Park and colleagues [134] demonstrated a similar shift in gut microbial composition following central CRF administration. Thus, the altered microbial composition of the gut in bulbectomized animals may be a consequence of their altered neuroendocrine response. Given the criticisms of the olfactory bulbectomy model, it is difficult to extrapolate these changes in the composition of the gut microbiota in bulbectomized animals to what is observed in clinical depression or even to other animal models of depression [135]. Thus, it is important to assess the role of the gut microbiota in other animal models of depression that are more clinically relevant. Social defeat stress, for example, exerted profound alterations in the operational taxonomic units of the gut microbiota, which led to deficits in sociability. A reduction in diversity was associated with decreases in the abundance of Clostridium species, as well as decreases in fatty acid production and biosynthesis pathways leading to dopamine and 5-HT production [136]. This decrease in Clostridium abundance following social defeat stress is in contrast to previous work from Bailey and colleagues [137], who demonstrated an increase in the relative abundance of Clostridium species following social disruption stress. A stress-induced increase in the abundance of Clostridium species may lead to translocation of this Gram-positive bacterium to the circulation, which could induce an inflammatory response and affect behaviour. Although there were considerable differences in terms of the animal models of depression that were used and the changes observed in the microbiota within these models, all of these animal studies collectively highlight an association between altered gut microbiota and depressionlike behaviour.

While no studies so far have assessed whether probiotics or prebiotics are successful in the treatment of clinical depression, several groups have documented the beneficial effects of probiotics and prebiotics in healthy individuals (see Table 1). Indeed, the idea that Lactobacillus strains may improve quality of life and mental health is not a new one. Dr. George Porter Phillips [138] first reported in 1910 that a gelatin-whey formula with live lactic acid bacteria improved depressive symptoms in adults with melancholia. More recently, 3-week supplementation with the prebiotic B-GOS decreased the cortisol awakening response and increased attentional vigilance towards positive stimuli [3]. This finding is consistent with those of a functional magnetic resonance imaging (fMRI) study, which demonstrated that long-term administration of a probiotic mixture of various Bifidobacterium and Lactobacillus species resulted in reduced neural activity within a widely distributed brain network in response to a task probing attention towards negative stimuli [64]. A recent study by Steenbergen and colleagues [139] further demonstrated the beneficial effects of a Lactobacillus and Bifidobacterium mixed probiotic on mood in healthy individuals. Moreover, clinical data from healthy participants would suggest that probiotics are also effective in alleviating behavioural symptoms of anxiety [140]. Given that these studies have shown that both prebiotics and probiotics improve mood in healthy individuals, this lends support to their use in treating depression and anxiety. However, clinical trials of probiotics and prebiotics in depressed patients are required to fully determine their efficacy in treating depression and anxiety.

Animal models have been useful in delineating the underlying antidepressant and anxiolytic mechanisms of action of probiotics. Interestingly, treatment with the probiotic Bifidobacterium infantis 35624 attenuated the immobility time of maternal separation rats in a forced swim test while also normalizing their aberrant peripheral immune response. However, the probiotic had no effect upon circulating corticosterone levels, which again suggests that bifidogenic-based probiotics affect behaviour independently of regulating stress-induced alterations in the HPA axis [129]. This is similar to what Savignac and colleagues [65] reported when they showed that both $\mathrm{Bi}$ fidobacterium longum and Bifidobacterium breve attenuated depressive and anxiety-like behaviours in mice. However, neither strain had any effect upon stress-induced (by forced swim test exposure) corticosterone release. Interestingly, a probiotic containing both Bifidobacterium longum and Lactobacillus helveticus attenuated circulating corticosterone and adrenaline levels in mice following exposure to water avoidance stress [120]. Such results suggest that probiotic-regulation of the HPA axis may be Lactobacillus dependent despite the beneficial effects of both bacterial strains upon behaviour. Nonetheless, these studies lend support to use of probiotics and prebiotics in the management of psychiatric conditions.

\subsection{Schizophrenia}

Schizophrenia is a complex neuropsychiatric disorder characterized by a cluster of symptoms, which includes psychoses, 
Table 1 Clinical and preclinical evidence for the antidepressant and anxiolytic properties associated with targeting the gut microbiota

\begin{tabular}{|c|c|c|c|}
\hline & Behavioural outcomes & Physiological outcomes & References \\
\hline \multicolumn{4}{|l|}{ Clinical evidence } \\
\hline B-GOS & $\begin{array}{l}\text { Increased cognitive processing of } \\
\text { positive versus negative } \\
\text { attentional vigilance }\end{array}$ & Reduced cortisol awakening response & {$[3]$} \\
\hline \multirow[t]{2}{*}{$\begin{array}{l}\text { Lactobacillus casei strain } \\
\text { Shirota }\end{array}$} & $\begin{array}{l}\text { Reduced anxiety scores in patients } \\
\text { with chronic fatigue syndrome }\end{array}$ & $\begin{array}{l}\text { Increased numbers of Lactobacillus and Bifidobacterium } \\
\text { in faecal samples }\end{array}$ & [141] \\
\hline & $\begin{array}{l}\text { Improved mood in individuals with } \\
\text { a low mood prior to taking the } \\
\text { probiotic }\end{array}$ & NA & {$[142]$} \\
\hline $\begin{array}{l}\text { Probiotic formulation: } \\
\text { Lactobacillus helveticus and } \\
\text { Bifidobacterium longum }\end{array}$ & $\begin{array}{l}\text { Reduced psychological distress as } \\
\text { measured by the HADS }\end{array}$ & Reduced 24-h UFC levels & {$[140]$} \\
\hline $\begin{array}{l}\text { Multispecies probiotic } \\
\text { formulation: Lactobacillus } \\
\text { and Bifidobacterium species }\end{array}$ & $\begin{array}{l}\text { Reduced cognitive processing of } \\
\text { sad mood; decreased aggressive } \\
\text { feelings and rumination }\end{array}$ & NA & {$[139]$} \\
\hline \multicolumn{4}{|l|}{ Preclinical evidence } \\
\hline FOS and GOS & NA & $\begin{array}{l}\text { Increased BDNF, NR1 and NR2A mRNA, and protein } \\
\text { expression in the dentate gyrus and frontal cortex }\end{array}$ & {$[100]$} \\
\hline $\begin{array}{l}\text { 3'Sialyllactose and } \\
6 \text { ' sialyllactose }\end{array}$ & $\begin{array}{l}\text { Anxiolytic effect in mice exposed to } \\
\text { SDR }\end{array}$ & $\begin{array}{l}\text { Prevented SDR-mediated reduction in the number of } \\
\text { immature neurons }\end{array}$ & {$[121]$} \\
\hline Bifidobacterium infantis & $\begin{array}{l}\text { Reduced immobility time of } \\
\text { maternally separated rats in a } \\
\text { forced swimming test }\end{array}$ & $\begin{array}{l}\text { Attenuated exaggerated IL-6 response in maternally } \\
\text { separated rats following concanavalin A stimulation }\end{array}$ & {$[129]$} \\
\hline Bifidobacterium breve & $\begin{array}{l}\text { Improved depressive and anxiety- } \\
\text { related behaviours in mice }\end{array}$ & No effect upon circulating corticosterone & {$[65]$} \\
\hline Bifidobacterium longum & $\begin{array}{l}\text { Anxiolytic effect in step-down } \\
\text { inhibitory avoidance }\end{array}$ & Anxiolytic effect mediated via the vagus nerve & {$[16]$} \\
\hline $\begin{array}{l}\text { Lactobacillus plantarum } \\
\text { PS128 }\end{array}$ & $\begin{array}{l}\text { Reduced immobility time and } \\
\text { increased sucrose preference in } \\
\text { ELS mice }\end{array}$ & $\begin{array}{l}\text { Decreased basal and stress-induced circulating } \\
\text { corticosterone levels; attenuated circulating TNF- } \alpha \text { and } \\
\text { IL-6 levels while increasing IL-10 levels in ELS mice }\end{array}$ & {$[143]$} \\
\hline Lactobacillus rhamnosus & $\begin{array}{l}\text { Reduced immobility time in } \\
\text { the forced swim test }\end{array}$ & $\begin{array}{l}\text { Decreased stress-induced circulating corticosterone } \\
\text { secretion and altered central GABA receptor subunit } \\
\text { expression }\end{array}$ & {$[11]$} \\
\hline Lactobacillus fermentum NS9 & $\begin{array}{l}\text { Reduced ampicillin-induced anxiety } \\
\text { behaviour }\end{array}$ & $\begin{array}{l}\text { Decreased ampicillin-induced corticosterone secretion } \\
\text { and increased hippocampal mineralocorticoid receptor } \\
\text { and NMDA receptor levels }\end{array}$ & {$[144]$} \\
\hline Butyric acid & $\begin{array}{l}\text { Reduced immobility time in } \\
\text { Flinders sensitive line rats } \\
\text { exposed to a forced swim test }\end{array}$ & Increased BDNF expression within the prefrontal cortex & {$[145]$} \\
\hline
\end{tabular}

$B D N F$ brain-derived neurotrophic factor, $E L S$ early life stress-exposed, FOS fructo-oligosaccharide, GABA $\gamma$-aminobutyric acid, GOS galactooligosaccharide, HADS Hospital Anxiety and Depression Scale, $I L$ interleukin, $m R N A$ messenger RNA, $N A$ not assessed, $N M D A N$-methyl-Daspartate, $S D R$ social disruption stress, TNF tumour necrosis factor, UFC urinary free cortisol, NR NMDA Receptor

cognitive dysfunction, delusions, paranoia and apathy. Given that the concordance rate for schizophrenia is greater in monozygotic twins than in dizygotic twins, it is widely accepted that schizophrenia has a genetic component in its pathology [146]. However, genome-wide association studies have found only a weak effect association for genetic factors contributing to this neuropsychiatric disorder [147]. Thus, it is likely that environmental factors (i.e. urban upbringing, drug use, early life trauma) interact with underlying genetic deficits, culminating in schizophrenic behaviour. Chronic gastrointestinal symptoms, such as gastritis and colitis, often accompany schizophrenia. However, whether this reflects altered brain-to-gut signalling or dysregulation of the microbiota is unknown [148, 149]. Nonetheless, there is some evidence to suggest a potential role of the gut microbiota in this neuropsychiatric disorder.

The development of the gut microbiota occurs synonymously with that of the brain. In fact, normal microbiota are required to facilitate proper neurodevelopment $[150,151]$. Thus, we must consider the importance of how we initially receive microbiota and how that affects the brain. Infants who are delivered normally acquire their 
microbiota by passing through the birth canal. Their microbiota are akin to vaginal and faecal bacteria, whereas when infants are born by caesarean section, their microbiota resemble those of the maternal skin and hospital environment, with fewer Bifidobacterium species and more Clostridium species [152, 153]. A recent clinical study found a weak association between birth by caesarean section and the risk of developing psychosis [154]. However, this association did not persist in sibling-matched analysis, which suggests that confounding genetic and environmental factors may account for this association between caesarean birth and psychosis. Nonetheless, there have been reports of increased urinary excretion of phenylalanine metabolites derived from Clostridium species in schizophrenic patients, which would suggest that perhaps there is an overabundance of this unfavourable bacterial strain in the microbiota in schizophrenic patients [155]. Whether Clostridium contributes towards the behavioural abnormalities observed in schizophrenia is unknown. However, how we receive our microbiota may be an influential factor in precipitating this neuropsychiatric disorder.

An additional environmental risk factor for schizophrenia is infection with the protozoan Toxoplasma gondii. Infection with the protozoan has been strongly correlated with schizophrenia, and medications used to treat psychosis are capable of inhibiting its replication in vitro $[156,157]$. Interestingly, toxoplasmosis in mice induces gastrointestinal inflammation, along with decreasing bacterial diversity in the ileum and increasing bacterial translocation into the circulation [158, 159]. Dysregulation in the composition of the gut microbiota following Toxoplasma gondii infection may contribute towards the ability of the protozoan to induce psychoses, perhaps through stimulation of the immune system or through production of bacterial metabolites that have a pro-psychotic effect. Viruses-specifically, those viruses that infect bacteria (bacteriophages) - are also associated with schizophrenia. Bacteriophages infect bacteria and subsequently alter their metabolism and replication, which could affect the composition of the microbiota and their ability to signal to the brain. The levels of the bacteriophage Lactobacillus phage phiadh were found to be elevated in the oropharyngeal microbiota in schizophrenic patients with comorbid immunological conditions [160]. The main Lactobacillus host for this bacteriophage is Lactobacillus gasseri, a strain of bacteria that is found in the oral and gastrointestinal mucosae and is linked with host immune modulation [161]. Given that schizophrenia is often comorbid with immunological conditions [162], Lactobacillus phage phiadh may affect the microbiota in schizophrenic patients, giving rise to aberrant immune responses.
Medications used to treat schizophrenia (such as the atypical antipsychotic olanzapine) are associated with causing a range of metabolic side effects, such as weight gain, increased fat accumulation and impairment of glucose metabolism [163]. It has been well documented that the gut microbiota have a role to play in energy regulation and metabolism, and that alterations in the bacterial commensals are associated with weight gain [164-166]. Interestingly, olanzapine treatment has been shown to lead to a reduction in the phylogenetic diversity of the gut microbiota in rats, with a reduction in the level of Bacteroidetes and an increase in the level of Firmicutes [167, 168]. This was associated with hyperphagia, an increase in visceral fat and increased peripheral inflammation, all of which were more prominent in female rats than in males [167]. Whether dysregulation of the microbiota following olanzapine treatment is a direct effect of the atypical antipsychotic or is secondary to the observed metabolic side effects is unknown, although it is likely to be the latter. However, a direct effect of olanzapine upon the gut flora cannot be ruled out. Nonetheless, it is interesting to note that olanzapine has a more pronounced effect upon metabolism and gut microbial composition in female rats, given that female patients are more susceptible to weight gain mediated by antipsychotic medication [169]. Gender dimorphism in metabolism and immune function may factor into this effect of olanzapine. Depletion of the microbiota following antibiotic treatment has been shown to correct the metabolic dysfunction induced by olanzapine while also reversing the effects of the antipsychotic upon gut bacterial composition [168]. The ability of antibiotics to reverse the metabolic side effects associated with antipsychotic use encourages development of prebiotic, probiotic or symbiotic (prebiotic and probiotic) therapies to tackle this clinical issue.

\subsection{Autism Spectrum Disorders}

Autism spectrum disorders (ASD) refer to a cluster of neurodevelopmental disorders characterized by the presence of repetitive behaviour and deficits in social interactions and communication. Comorbid gastrointestinal disorders are reported in up to $90 \%$ of children with ASD and include constipation, diarrhoea, abdominal pain, vomiting and poor nutritional absorption [170]. The evidence suggests that these gastrointestinal disorders in ASD are associated with dysregulation of the gut microbiota and that the extent of gastrointestinal dysfunction can predict the severity of autistic behaviour. Levels of Bacteroidetes and Firmicutes are found to be altered in faecal samples from autistic children [123, 171, 172]. Indeed, autistic children show greater faecal microbiota diversity than healthy children [173]. Greater diversity of the microbiota 
may increase the likelihood of the presence of harmful bacteria, which may contribute towards the severity of autistic behaviour. For instance, Parracho [174] noted that faecal samples from children with ASD displayed greater levels of the Clostridium histolyticum group (Clostridium clusters I and II) than control subjects. Moreover, in a Slovakian cohort of children with ASD, the levels of Lactobacillus and Clostridium class 1 were higher in faecal samples from autistic children than in those from control children. The levels of Clostridium and Desulfovibrio have been found to be higher in children with more profound autism than in children with milder autism, which suggest that perhaps these two bacterial species somehow dictate the severity of autistic symptoms [123].

Further indications of a role of Clostridium in autism have come from a small clinical study in which 11 children with regressive autism were treated with the antibiotic vancomycin. Autistic behaviour dramatically improved during the 8-week vancomycin trial, with increased eye contact and speech, along with a considerable decrease in gastrointestinal symptoms. However, all children relapsed following cessation of the trial [175]. Given that vancomycin targets Clostridium species, this small study seemingly confirms the detrimental role of this bacterial species in ASD. How might the altered microbiota found in children with ASD give rise to autistic behaviours/symptoms? A role of SCFAs has been implicated, as increased levels of the microbial metabolites have been observed in faecal samples from autistic children. Of note, levels of acetic acid, butyric acid and propionic acid were all higher in autistic children than in controls [176]. SCFAs regulate the acidity of the gut by lowering the intestinal $\mathrm{pH}$. Increasing the acidic environment of the gut may promote proliferation of Clostridium species, which may subsequently facilitate autistic behaviour. Additionally, SCFAs are able to cross the BBB and possess neuroactive properties [24, 27, 28]. Thus, excessive production of SCFAs by the gut microbiota in autistic children may cross the BBB and have a detrimental effect upon neurodevelopment.

Animal models of autism allow us to more closely investigate how the microbiota-gut-brain axis may be perturbed in autistic individuals. Autistic symptoms such as repetitive behaviour, deficits in communication and reduced sociability can be mimicked in animals through experimental manipulations, such as in utero exposure to teratogens (valproic acid [VPA]) or inflammagens (polyinosinic:polycytidylic acid [poly I:C]). Uterine exposure to VPA induces deficits in social interaction in mice. Interestingly, this deficit in sociability is evident in male mice but not in female mice, which is similar to what is observed in the clinical setting $[177,178]$. In utero VPA exposure has also been shown to result in gastrointestinal inflammation, along with alterations in the gut microbiota, observed as an increase in Firmicutes and a decrease in Bacteroidetes. Moreover, uterine VPA exposure increased caecal SCFA levels-specifically, butyric acid-in male mice but not in female mice [177, 178]. Uterine exposure of animals to the inflammagen poly I:C also produces autism-like symptoms in rodents and primates, and is referred to as the maternal immune activation (MIA) model of autism [179, 180]. This model is quite interesting because of its construct validity, as severe viral or bacterial infection during the first and second trimesters of pregnancy is considered to be a risk factor for autism in humans [181]. MIA induces dysregulation of the gut microbiota, along with promoting autism-like features in mice [182]. Hsiao and colleagues [182] did not identify any differences in the overall microbial diversity between MIA and controls in terms of species richness. However, they did pinpoint differences in the diversity of the Clostridium and Bacteroides operational taxonomic units, which they concluded was the major driving force behind dysregulation of the microbiota in MIA animals. This increased diversity of Clostridium species in MIA animals parallels what is observed in children with autism [123, 174]. Additionally, treatment with Bacteroides fragilis corrected the MIA-induced dysregulation of the gastrointestinal system and microbiota, along with reversing some of the autism-like behaviours induced by uterine poly I:C exposure [182]. The ability of Bacteroides fragilis to improve autism-like behaviour while also improving gastrointestinal and microbiota dysregulation highlights the potential of targeting the gut microbiota for treatments for autism.

Interestingly, elevated levels of some SCFAs have also been shown to induce autism-like symptoms. Propionic acid, when administered in high or neurotoxic doses, produces a neuroinflammatory response while also altering brain lipid composition and facilitating an autism-like phenotype in adult rats [49, 183-185]. The dysregulation of the gut microbiota that is observed in autism may lead to excessive production of propionic acid that crosses into the brain and gives rise to the neurophysiological and behavioural profile of autism. While propionic acid may contribute towards autistic behaviour, butyric acid has recently been shown to improve repetitive behaviour in the BTBR mouse model of autism [28]. Thus, SCFAs appear to have a Janus-faced role in mediating autism-like behaviour. More work is required to determine the precise molecular mechanisms underlying the opposing effects of propionic acid and butyric acid in autism-like behaviour.

While there has been substantial research into the dysregulation of the microbiota-gut-brain axis in ASD and the potential beneficial effects of psychobiotics, more insight is required to determine whether this dysregulation is causal of the neurodevelopmental disorder or a consequential comorbidity. Factors such as diet, hygiene, medication and 
susceptibility to stress have all been shown to affect the microbiota, and these factors may account for the observed dysregulation of the gut flora in ASD. For instance, anxiety is found to be comorbid in between 11 and $84 \%$ of children and adolescents with ASD [186]. Increased anxiety in ASD, and the ensuing stress that accompanies it, may contribute towards the dysregulation of the gut microbiota that is observed in autism. Thus, alterations in the bacterial flora of the gut in autism may be a consequence of comorbidity rather than the underlying cause of the developmental disorder itself. The studies that demonstrated altered microbiota in children with ASD had additional limitations. Most of these studies were underpowered and did not control for factors that have an impact upon the microbiota, such as diet, sex and prior exposure to antibiotics [187]. Even short-term antibiotic use has been shown to induce long-lasting changes in the gut microbiota, which might account for the differences reported between autistic children and normal children [72]. Diet is also an important consideration, as many autistic children display stereotyped diets that may affect the diversity and composition of the gut microbiota. In a recent study, 16S ribosomal RNA (rRNA) analysis revealed an increase in the low-abundance Cyanobacteria/ chloroplast genus in children with ASD [188]. However, the authors cautioned that this increase in chloroplast sequences in ASD may have been due to ingestion of chia seeds, which indicates that diet is an influential factor that must be controlled for when investigating disturbances of the microbiota in ASD. Furthermore, studies assessing an effect of probiotics upon autistic behaviour in children have been underpowered and lacking in experimental design to reveal any potential beneficial effect [123, 189, 190]. Future studies assessing the effect of psychobiotics upon autistic behaviour in humans will require a double-blind, placebo-controlled design with sufficient power.

\section{Conclusions and Future Perspectives: A New Hope?}

Through mediators such as the immune system, bacterial metabolites and the vagus nerve, the gut microbiota regulate neurophysiological processes from neurotransmission to cognition and mood. Dysregulation of this microbiota-gut-brain axis accompanies the neuropathology observed in mood and neurodevelopmental disorders, such as depression, schizophrenia and autism. Preclinical studies in animal models have provided us with an understanding into how alterations in the gut microbiota may contribute towards these neuropsychiatric conditions. However, greater clinical insight is required to determine the extent to which these preclinical observations translate into what is observed in the human condition. Moreover, it remains to be determined whether these alterations in the gut microbiota are causal of these neuropsychiatric conditions (autism in particular) or a comorbid consequence. To paraphrase Yoda (from Star Wars: Episode V-The Empire Strikes Back), "Much to learn, we still have" regarding the role of the microbiota-gut-brain axis in neuropsychiatry. Preclinical studies remain vital in dissecting the mechanism of action of various bacterial strains upon behaviour. Early clinical data suggest that psychobiotics could potentially be used as a first-line treatment for neuropsychiatric conditions. However, this will require a greater investment in large-scale clinical trials by food and drug companies to determine whether psychobiotics have efficacy in conditions such as depression and autism [191].

\section{Compliance with Ethical Standards}

Funding Timothy Dinan and John Cryan are supported by the Science Foundation Ireland (SFI) [Grant Numbers 07/CE/B1368 and 12/RC/2273]; the Irish Health Research Board; the Department of Agriculture, Food and the Marine; and Enterprise Ireland. Open Access Fee was funded via the Centre grant to APC Microbiome Institute from Science Foundation Ireland.

Conflict of interest Timothy Dinan and John Cryan are in receipt of research funding from 4D-Pharma, Mead Johnson, Suntory Wellness, Nutricia and Cremo. Timothy Dinan has been an invited speaker at meetings organized by Servier, Lundbeck, Janssen and AstraZeneca. John Cryan has been an invited speaker at meetings organized by Mead Johnson, Yakult, Alkermes and Janssen. Eoin Sherwin and Kiran Sandhu have no conflicts of interest to declare.

Open Access This article is distributed under the terms of the Creative Commons Attribution-NonCommercial 4.0 International License (http://creativecommons.org/licenses/by-nc/4.0/), which permits any noncommercial use, distribution, and reproduction in any medium, provided you give appropriate credit to the original author(s) and the source, provide a link to the Creative Commons license, and indicate if changes were made.

\section{References}

1. Frank DN, Pace NR. Gastrointestinal microbiology enters the metagenomics era. Curr Opin Gastroenterol. 2008;24(1):4-10.

2. Qin J, Li R, Raes J, Arumugam M, Burgdorf KS, Manichanh C, et al. A human gut microbial gene catalogue established by metagenomic sequencing. Nature [Internet]. 2010;464(7285):59-65. doi:10.1038/nature08821.

3. Schmidt K, Cowen PJ, Harmer CJ, Tzortzis G, Errington S, Burnet PWJ. Prebiotic intake reduces the waking cortisol response and alters emotional bias in healthy volunteers. Psychopharmacology (Berl) [Internet]. 2015;232(10):1793-801. doi:10.1007/s00213-014-3810-0.

4. El Aidy S, Dinan TG, Cryan JF. Immune modulation of the brain-gut-microbe axis. Front Microbiol [Internet]. 2014;5(April):3-6. doi:10.3389/fmicb.2014.00146/abstract. 
5. Dinan TG, Stilling RM, Stanton C, Cryan JF. Collective unconscious: how gut microbes shape human behavior. J Psychiatr Res [Internet]. Elsevier Ltd. 2015;63:1-9. Available from: http://linkinghub.elsevier.com/retrieve/pii/S0022395615000655.

6. Sherwin E, Rea K, Dinan TG, Cryan JF. A gut (microbiome) feeling about the brain. Curr Opin Gastroenterol [Internet]. 2016;1. Available from: http://content.wkhealth.com/linkback/ openurl?sid=WKPTLP:landingpage $\&$ an $=00001574-900000000$ 99440.

7. Daulatzai MA. Chronic functional bowel syndrome enhances gut-brain axis dysfunction, neuroinflammation, cognitive impairment, and vulnerability to dementia. Neurochem Res [Internet]. 2014;39(4):624-44. doi:10.1007/s11064-014-1266-6.

8. Kelly JR, Kennedy PJ, Cryan JF, Dinan TG, Glarke G, Hyland NP. Breaking down the barriers: the gut microbiome, intestinal permeability and stress-related psychiatric disorders. Front Cell Neurosci. 2015;9:392.

9. Goehler LE, Gaykema RPA, Opitz N, Reddaway R, Badr N, Lyte M. Activation in vagal afferents and central autonomic pathways: early responses to intestinal infection with Campylobacter jejuni. Brain Behav Immun. 2005;19(4):334-44.

10. D'Mello C, Ronaghan N, Zaheer R, Dicay M, Le T, MacNaughton WK, et al. Probiotics improve inflammation-associated sickness behavior by altering communication between the peripheral immune system and the brain. J Neurosci [Internet]. 2015;35(30):10821-30. doi:10.1523/JNEUROSCI. 0575-15.2015.

11. Bravo JA, Forsythe P, Chew M V, Escaravage E, Savignac HM, Dinan TG, et al. Ingestion of Lactobacillus strain regulates emotional behavior and central GABA receptor expression in a mouse via the vagus nerve. Proc Natl Acad Sci [Internet]. 2011;108(38):16050-5. Available from: http://www.pnas.org/ cgi/content/long/108/38/16050.

12. Dinan TG, Cryan JF. The impact of gut microbiota on brain and behaviour. Curr Opin Clin Nutr Metab Care [Internet]. 2015;18(6):552-8. Available from: http://content.wkhealth.com/ linkback/openurl?sid=WKPTLP:landingpage $\&$ an $=00075197$ 201511000-00005.

13. Poutahidis T, Kearney SM, Levkovich T, Qi P, Varian BJ, Lakritz JR, Ibrahim YM, Chatzigiagkos A, Alm EJ, Erdman SE. Microbial symbionts accelerate wound healing via the neuropeptide hormone oxytocin. PLoS One [Internet]. 2013;8(10):e78898. doi:10.1371/journal.pone.0078898.

14. Marvel FA, Chen CC, Badr N, Gaykema RPA, Goehler LE. Reversible inactivation of the dorsal vagal complex blocks lipopolysaccharide-induced social withdrawal and c-Fos expression in central autonomic nuclei. Brain Behav Immun. 2004;18(2):123-34

15. Klarer M, Arnold M, Günther L, Winter C, Langhans W, Meyer $\mathrm{U}$. Gut vagal afferents differentially modulate innate anxiety and learned fear. J Neurosci [Internet]. 2014;34(21):7067-76. Available from: http://www.ncbi.nlm.nih.gov/pubmed/24849343.

16. Bercik P, Park AJ, Sinclair D, Khoshdel A, Lu J, Huang X, et al. The anxiolytic effect of Bifidobacterium longum NCC3001 involves vagal pathways for gut-brain communication. Neurogastroenterol Motil. 2011;23(12):1132-9.

17. Bercik P, Denou E, Collins J, Jackson W, Lu J, Jury J, et al. The intestinal microbiota affect central levels of brain-derived neurotropic factor and behavior in mice. Gastroenterology [Internet]. 2011;141(2):599-609.e3. Available from: http:// linkinghub.elsevier.com/retrieve/pii/S001650851100607X.

18. Stilling RM, Dinan TG, Cryan JF. Microbial genes, brain \& behaviour-epigenetic regulation of the gut-brain axis. Genes Brain Behav [Internet]. 2014;13(1):69-86. doi:10.1111/gbb. 12109.
19. Tan J, McKenzie C, Potamitis M, Thorburn AN, Mackay CR, Macia L. The role of short-chain fatty acids in health and disease. Adv Immunol. 2014;121(January):91-119.

20. De Vadder F, Kovatcheva-Datchary P, Goncalves D, Vinera J, Zitoun C, Duchampt A, et al. Microbiota-generated metabolites promote metabolic benefits via gut-brain neural circuits. Cell [Internet]. 2014;156(1-2):84-96. Available from: http:// linkinghub.elsevier.com/retrieve/pii/S009286741301550X.

21. DeCastro M, Nankova BB, Shah P, Patel P, Mally P V, Mishra R, et al. Short chain fatty acids regulate tyrosine hydroxylase gene expression through a cAMP-dependent signaling pathway. Brain Res Mol Brain Res [Internet]. 2005;142(1):28-38. Available from: http://www.ncbi.nlm.nih.gov/pubmed/16219387.

22. Shah P, Nankova BB, Parab S, La Gamma EF. Short chain fatty acids induce TH gene expression via ERK-dependent phosphorylation of CREB protein. Brain Res [Internet]. 2006;1107(1):13-23. Available from: http://linkinghub.elsevier. com/retrieve/pii/S0006899306016544.

23. Nankova BB, Agarwal R, MacFabe DF, La Gamma EF. Enteric bacterial metabolites propionic and butyric acid modulate gene expression, including CREB-dependent catecholaminergic neurotransmission, in $\mathrm{PC} 12$ cells-possible relevance to autism spectrum disorders. PLoS One [Internet]. 2014;9(8):e103740. Available from: http://www.pubmedcentral.nih.gov/articlerender. fcgi $?$ artid $=4149359 \&$ tool=pmcentrez\&rendertype $=$ abstract.

24. El-Ansary AK, Bacha A, Kotb M. Etiology of autistic features: the persisting neurotoxic effects of propionic acid. J Neuroinflamm [Internet]. BioMed Central Ltd; 2012;9(1):74. Available from: http://www.jneuroinflammation.com/content/9/1/74.

25. Schroeder FA, Lin CL, Crusio WE, Akbarian S. Antidepressantlike effects of the histone deacetylase inhibitor, sodium butyrate, in the mouse. Biol Psychiatry. 2007;62(1):1.

26. Gundersen BB, Blendy JA. Effects of the histone deacetylase inhibitor sodium butyrate in models of depression and anxiety. Neuropharmacology [Internet]. Elsevier Ltd. 2009;57(1):67-74. doi:10.1016/j.neuropharm.2009.04.008.

27. Macfabe DF. Short-chain fatty acid fermentation products of the gut microbiome: implications in autism spectrum disorders. Microb Ecol Health Dis [Internet]. 2012;23:1-24. Available from: http://www.pubmedcentral.nih.gov/articlerender.fcgi? artid $=3747729 \&$ tool $=$ pmcentrez $\&$ rendertype $=$ abstract.

28. Kratsman N, Getselter D, Elliott E. Sodium butyrate attenuates social behavior deficits and modifies the transcription of inhibitory/excitatory genes in the frontal cortex of an autism model. Neuropharmacology [Internet]. Elsevier Ltd. 2016;102:136-45. Available from: http://linkinghub.elsevier.com/retrieve/pii/ S0028390815301672.

29. Huuskonen J, Suuronen T, Nuutinen T, Kyrylenko S, Salminen A. Regulation of microglial inflammatory response by sodium butyrate and short-chain fatty acids. Br J Pharmacol [Internet]. 2004;141(5):874-80. Available from: http://www. pubmedcentral.nih.gov/articlerender.fcgi?artid $=1574260 \&$ tool $=$ pmcentrez\&rendertype $=$ abstract.

30. Erny D, Hrabě de Angelis AL, Jaitin D, Wieghofer P, Staszewski O, David E, et al. Host microbiota constantly control maturation and function of microglia in the CNS. Nat Neurosci [Internet]. 2015;18(7):965-77. doi:10.1038/nn.4030.

31. de Almeida LMV, Funchal C, Gottfried C, Wajner M, PessoaPureur R. Propionic acid induces cytoskeletal alterations in cultured astrocytes from rat cerebral cortex. Metab Brain Dis [Internet]. 2006;21(1):51-62. Available from: http://www.ncbi. nlm.nih.gov/pubmed/16773470.

32. Shultz SR, MacFabe DF, Martin S, Jackson J, Taylor R, Boon F, et al. Intracerebroventricular injections of the enteric bacterial metabolic product propionic acid impair cognition and sensori- 
motor ability in the Long-Evans rat: further development of a rodent model of autism. Behav Brain Res [Internet]. 2009;200(1):33-41. doi:10.1016/j.bbr.2008.12.023.

33. Kanski R, Sneeboer MAM, van Bodegraven EJ, Sluijs JA, Kropff W, Vermunt MW, et al. Histone acetylation in astrocytes suppresses GFAP and stimulates a reorganization of the intermediate filament network. J Cell Sci [Internet]. 2014;127(Pt 20):4368-80. Available from: http://www.ncbi.nlm.nih.gov/ pubmed/25128567.

34. Latorre R, Sternini C, De Giorgio R, Greenwood-Van Meerveld B. Enteroendocrine cells: a review of their role in brain-gut communication. Neurogastroenterol Motil [Internet]. 2015. doi:10.1111/nmo.12754.

35. Sternini C, Anselmi L, Rozengurt E. Enteroendocrine cells: a site of "taste" in gastrointestinal chemosensing. Curr Opin Endocrinol Diabetes Obes. 2008;15(1):73-8.

36. Bauer PV, Hamr SC, Duca FA. Regulation of energy balance by a gut-brain axis and involvement of the gut microbiota. Cell Mol Life Sci [Internet]. Springer Basel. 2015. doi:10.1007/ s00018-015-2083-z.

37. Duca FA, Swartz TD, Sakar Y, Covasa M. Increased oral detection, but decreased intestinal signaling for fats in mice lacking gut microbiota. PLoS One. 2012;7(6):e39748.

38. Breton J, Tennoune N, Lucas N, Francois M, Legrand R, Jacquemot $\mathrm{J}$, et al. Gut commensal E. coli proteins activate host satiety pathways following nutrient-induced bacterial growth. Cell Metab [Internet]. 2016;23:1-11.

39. Panaro BL, Tough IR, Engelstoft MS, Matthews RT, Digby GJ, Møller CL, et al. The melanocortin-4 receptor is expressed in enteroendocrine $\mathrm{L}$ cells and regulates the release of peptide YY and glucagon-like peptide 1 in vivo. Cell Metab [Internet]. Elsevier Inc. 2014;20(6):1018-29. doi:10.1016/j.cmet.2014.10.004.

40. Swartz TD, Duca FA, de Wouters T, Sakar Y, Covasa M. Upregulation of intestinal type 1 taste receptor 3 and sodium glucose luminal transporter-1 expression and increased sucrose intake in mice lacking gut microbiota. Br J Nutr [Internet]. 2012;107(5):621-30. Available from: http://www.ncbi.nlm.nih. gov/pubmed/21781379.

41. Nøhr MK, Pedersen MH, Gille A, Egerod KL, Engelstoft MS, Husted AS, et al. GPR41/FFAR3 and GPR43/FFAR2 as cosensors for short-chain fatty acids in enteroendocrine cells vs FFAR3 in enteric neurons and FFAR2 in enteric leukocytes. Endocrinology [Internet]. 2013;154(10):3552-64. doi:10.1210/ en.2013-1142.

42. Cani PD, Dewever C, Delzenne NM. Inulin-type fructans modulate gastrointestinal peptides involved in appetite regulation (glucagon-like peptide-1 and ghrelin) in rats. Br J Nutr [Internet]. 2004;92(03):521. Available from: http://www. journals.cambridge.org/abstract_S0007114504001989.

43. Cani PD, Neyrinck AM, Maton N, Delzenne NM. Oligofructose promotes satiety in rats fed a high-fat diet: involvement of glucagon-like peptide-1. Obes Res [Internet]. 2005;13(6):1000-7. Available from: http://www.ncbi.nlm.nih. gov/pubmed/15976142.

44. Cani PD, Joly E, Horsmans Y, Delzenne NM. Oligofructose promotes satiety in healthy human: a pilot study. Eur J Clin Nutr. 2006;60(5):567-72.

45. O'Mahony SM, Clarke G, Borre YE, Dinan TG, Cryan JF. Serotonin, tryptophan metabolism and the brain-gut-microbiome axis. Behav Brain Res [Internet]. Elsevier B.V. 2015;277:32-48. Available from: http://linkinghub.elsevier. com/retrieve/pii/S0166432814004768.

46. Blier P, El Mansari M. Serotonin and beyond: therapeutics for major depression. Philos Trans R Soc Lond B Biol Sci [Internet]. 2013;368(1615):20120536. Available from: http://www. pubmedcentral.nih.gov/articlerender.fcgi?artid=3638389\&tool= pmcentrez\&rendertype $=$ abstract.

47. Dantzer R, Connor JCO, Lawson MA, Kelley KW. Inflammation-associated depression: from serotonin to kynurenine. Psychoneuroendocrinology. 2012;36(3):426-36.

48. Schwarcz R, Bruno JP, Muchowski PJ, Wu H-Q. Kynurenines in the mammalian brain: when physiology meets pathology. Nat Rev Neurosci [Internet]. Nature Publishing Group. 2012 [cited 2012 Oct 24];13(7):465-77. Available from: http://www.ncbi. nlm.nih.gov/pubmed/22678511.

49. Wikoff WR, Anfora AT, Liu J, Schultz PG, Lesley SA, Peters EC, et al. Metabolomics analysis reveals large effects of gut microflora on mammalian blood metabolites. Proc Natl Acad Sci [Internet]. 2009;106(10):3698-703. Available from: http://www. pubmedcentral.nih.gov/articlerender.fcgi?artid=2656143\&tool= pmcentrez\&rendertype $=$ abstract.

50. Clarke G, Grenham S, Scully P, Fitzgerald P, Moloney RD, Shanahan F, et al. The microbiome-gut-brain axis during early life regulates the hippocampal serotonergic system in a sexdependent manner. Mol Psychiatry [Internet]. Nature Publishing Group. 2013;18(6):666-73. doi:10.1038/mp.2012.77.

51. Yano JM, Yu K, Mazmanian SK, Hsiao Correspondence EY, Donaldson GP, Shastri GG, et al. Indigenous bacteria from the gut microbiota regulate host serotonin biosynthesis. Cell [Internet]. Elsevier. 2015;161(2):264-76. doi:10.1016/j.cell.2015. 02.047 .

52. Desbonnet L, Garrett L, Clarke G, Bienenstock J, Dinan TG. The probiotic Bifidobacteria infantis: an assessment of potential antidepressant properties in the rat. J Psychiatr Res [Internet]. Elsevier Ltd. 2008;43(2):164-74. Available from: http:// linkinghub.elsevier.com/retrieve/pii/S0022395608000745.

53. Valladares R, Bojilova L, Potts AH, Cameron E, Gardner C, Lorca G, et al. Lactobacillus johnsonii inhibits indoleamine 2,3dioxygenase and alters tryptophan metabolite levels in BioBreeding rats. FASEB J [Internet]. 2013;27(4):1711-20. Available from: http://www.ncbi.nlm.nih.gov/pubmed/ 23303207.

54. McFarlane HG, Kusek GK, Yang M, Phoenix JL, Bolivar VJ, Crawley JN. Autism-like behavioral phenotypes in BTBR T+tf/ J mice. Genes Brain Behav [Internet]. 2008;7(2):152-63. doi:10. 1111/j.1601-183X.2007.00330.x.

55. Slavin J. Fiber and prebiotics: mechanisms and health benefits. Nutrients [Internet]. 2013;5(4):1417-35. Available from: http:// www.pubmedcentral.nih.gov/articlerender.fcgi? $\operatorname{artid}=3705355 \&$ tool=pmcentre $\&$ rendertype $=$ abstract.

56. Depeint F, Tzortzis G, Vulevic J, Gibson GR. Prebiotic evaluation of a novel galactooligosaccharide mixture produced by the enzymatic activity of. Am J Clin Nutr. 2008;87:785-91.

57. Ramnani P, Costabile A, Bustillo AGR, Gibson GR. A randomised, double-blind, cross-over study investigating the prebiotic effect of agave fructans in healthy human subjects. J Nutr Sci [Internet]. 2015;4:e10. Available from: http://www.journals. cambridge.org/abstract_S2048679014000688.

58. Nyangale EP, Farmer S, Keller D, Chernoff D, Gibson GR. Effect of prebiotics on the fecal microbiota of elderly volunteers after dietary supplementation of Bacillus coagulans GBI-30, 6086. Anaerobe [Internet]. Elsevier Ltd. 2014;30:75-81. Available from: http://www.ncbi.nlm.nih.gov/pubmed/2521 9857.

59. Vulevic J, Juric A, Walton GE, Claus SP, Tzortzis G, Toward $\mathrm{RE}$, et al. Influence of galacto-oligosaccharide mixture (B-GOS) on gut microbiota, immune parameters and metabonomics in elderly persons. Br J Nutr [Internet]. 2015;114(04):586-95. Available from: http://www.journals.cambridge.org/abstract_ S0007114515001889. 
60. Hopkins MJ, Sharp R, Macfarlane GT. Age and disease related changes in intestinal bacterial populations assessed by cell culture, 16S rRNA abundance, and community cellular fatty acid profiles. Gut [Internet]. 2001;48(2):198-205. Available from: http://www.pubmedcentral.nih.gov/articlerender.fcgi?artid= $1728209 \&$ tool $=$ pmcentre $\&$ rendertype $=$ abstract.

61. Scott KP, Antoine J-M, Midtvedt T, van Hemert S. Manipulating the gut microbiota to maintain health and treat disease. Microb Ecol Health Dis [Internet]. 2015;26:25877. Available from: http://www.pubmedcentral.nih.gov/articlerender.fcgi?artid $=4315778 \&$ tool $=$ pmcentrez\&rendertype $=$ abstract.

62. Cani PD, Possemiers S, Van de Wiele T, Guiot Y, Everard A, Rottier O, et al. Changes in gut microbiota control inflammation in obese mice through a mechanism involving GLP-2-driven improvement of gut permeability. Gut [Internet]. 2009;58(8):1091-103. Available from: http://gut.bmj.com/cgi/ doi/10.1136/gut.2008.165886.

63. Butel MJ. Probiotics, gut microbiota and health. Med Mal Infect [Internet]. Elsevier Masson SAS. 2014;44(1):1-8. doi:10.1016/j. medmal.2013.10.002.

64. Tillisch K, Labus J, Kilpatrick L, Jiang Z, Stains J, Ebrat B, et al. Consumption of fermented milk product with probiotic modulates brain activity. Gastroenterology [Internet]. Elsevier Inc. 2013;144(7):1394-401.e4. doi:10.1053/j.gastro.2013.02.043.

65. Savignac HM, Kiely B, Dinan TG, Cryan JF. Bifidobacteria exert strain-specific effects on stress-related behavior and physiology in BALB/c mice. Neurogastroenterol Motil [Internet]. 2014;26(11):1615-27. Available from: http://www.ncbi. nlm.nih.gov/pubmed/25251188 http://onlinelibrary.wiley.com/ store/10.1111/nmo.12427/asset/nmo12427.pdf? $\mathrm{v}=1 \& \mathrm{t}=\mathrm{i} 421 \mathrm{p} 93$ $\mathrm{c} \& \mathrm{~s}=\mathrm{a} 1 \mathrm{dd} 31 \mathrm{adf} 78 \mathrm{c} 572 \mathrm{ed} 1 \mathrm{~b} 10 \mathrm{e} 1428 \mathrm{e} 70666629969 \mathrm{~d} 7$.

66. Smith CJ, Emge JR, Berzins K, Lung L, Khamishon R, Shah P, et al. Probiotics normalize the gut-brain-microbiota axis in immunodeficient mice. AJP Gastrointest Liver Physiol [Internet]. 2014;307(8):G793-802. doi:10.1152/ajpgi.00238.2014.

67. Qin H-L, Shen T-Y, Gao Z-G, Fan X-B, Hang X-M, Jiang Y-Q, et al. Effect of lactobacillus on the gut microflora and barrier function of the rats with abdominal infection. World $\mathrm{J}$ Gastroenterol [Internet]. 2005;11(17):2591-6. Available from: http://www.ncbi.nlm.nih.gov/pubmed/15849817.

68. Distrutti E, O’Reilly J-A, McDonald C, Cipriani S, Renga B, Lynch MA, et al. Modulation of intestinal microbiota by the probiotic VSL\#3 resets brain gene expression and ameliorates the age-related deficit in LTP. PLoS One [Internet]. 2014;9(9):e106503. doi:10.1371/journal.pone.0106503.

69. Ohland CL, Jobin C. Microbial activities and intestinal homeostasis: a delicate balance between health and disease. Cell Mol Gastroenterol Hepatol. 2015;1(1):28-40. doi:10.1016/j.jcmgh. 2014.11.004

70. Akkasheh G, Kashani-Poor Z, Tajabadi-Ebrahimi M, Jafari P, Akbari H, Taghizadeh $\mathrm{M}$, et al. Clinical and metabolic response to probiotic administration in patients with major depressive disorder: a randomized, double-blind, placebo-controlled trial. Nutrition. 2016;32(3):315-20. doi:10.1016/j.nut.2015.09.003.

71. Manichanh C, Reeder J, Gibert P, Varela E, Llopis M, Antolin $\mathrm{M}$, et al. Reshaping the gut microbiome with bacterial transplantation and antibiotic intake. Genome Res. 2010;20(10):1411-9.

72. Panda S, El Khader I, Casellas F, López Vivancos J, García Cors M, Santiago A, et al. Short-term effect of antibiotics on human gut microbiota. PLoS One [Internet]. 2014;9(4):e95476. doi:10. 1371/journal.pone.0095476.

73. Korpela K, Salonen A, Virta LJ, Kekkonen RA, Forslund K, Bork $\mathrm{P}$, et al. Intestinal microbiome is related to lifetime antibiotic use in Finnish pre-school children. Nat Commun
[Internet]. Nature Publishing Group. 2016;7:1-8. doi:10.1038/ ncomms 10410 .

74. Cox LM, Yamanishi S, Sohn J, Alekseyenko A V., Leung JM, Cho I, et al. Altering the intestinal microbiota during a critical developmental window has lasting metabolic consequences. Cell [Internet]. 2014;158(4):705-21. Available from: http:// www.ncbi.nlm.nih.gov/pubmed/25126780.

75. Tochitani S, Ikeno T, Ito T, Sakurai A, Yamauchi T, Matsuzaki H. Administration of non-absorbable antibiotics to pregnant mice to perturb the maternal gut microbiota is associated with alterations in offspring behavior. PLoS One [Internet]. 2016;11(1):e0138293. doi:10.1371/journal.pone.0138293.

76. O'Mahony SM, Felice VD, Nally K, Savignac HM, Claesson MJ, Scully P, et al. Disturbance of the gut microbiota in earlylife selectively affects visceral pain in adulthood without impacting cognitive or anxiety-related behaviors in male rats. Neuroscience [Internet]. IBRO; 2014;277:885-901. Available from: http://linkinghub.elsevier.com/retrieve/pii/S0306452214 006277.

77. Desbonnet L, Clarke G, Traplin A, O'Sullivan O, Crispie F, Moloney RD, et al. Gut microbiota depletion from early adolescence in mice: implications for brain and behaviour. Brain Behav Immun [Internet]. Elsevier Inc. 2015;48:165-73. Available from: http://linkinghub.elsevier.com/retrieve/pii/S0889 159115000896

78. Verdú EF, Bercik P, Verma-Gandhu M, Huang X-X, Blennerhassett $\mathrm{P}$, Jackson $\mathrm{W}$, et al. Specific probiotic therapy attenuates antibiotic induced visceral hypersensitivity in mice. Gut. 2006;55(2):182-90.

79. Luczynski P, Neufeld KM, Oriach CS, Clarke G, Dinan TG, Cryan JF. Growing up in a bubble: using germ-free animals to assess the influence of the gut microbiota on brain and behavior. Int J Neuropsychopharmacol. 2016; doi:10.1093/ijnp/pyw020.

80. Möhler H. The GABA system in anxiety and depression and its therapeutic potential. Neuropharmacology [Internet]. Elsevier Ltd. 2012 [cited 2013 Sep 20];62(1):42-53. Available from: http://www.ncbi.nlm.nih.gov/pubmed/21889518.

81. Barrett E, Ross RP, O'Toole PW, Fitzgerald GF, Stanton C. $\gamma$ Aminobutyric acid production by culturable bacteria from the human intestine. J Appl Microbiol [Internet]. 2012; 113(2):411-7. doi:10.1111/j.1365-2672.2012.05344.x.

82. Hiraga K, Ueno Y, Oda K. Glutamate decarboxylase from Lactobacillus brevis: activation by ammonium sulfate. Biosci Biotechnol Biochem. 2008;72(5):1299-306.

83. Komatsuzaki N, Nakamura T, Kimura T, Shima J. Characterization of glutamate decarboxylase from a high gammaaminobutyric acid (GABA)-producer, Lactobacillus paracasei. Biosci Biotechnol Biochem. 2008;72(2):278-85.

84. Boonstra E, de Kleijn R, Colzato LS, Alkemade A, Forstmann BU, Nieuwenhuis S. Neurotransmitters as food supplements: the effects of GABA on brain and behavior. Front Psychol [Internet]. 2015;6(October):6-11. doi:10.3389/fpsyg.2015.01520.

85. Takanaga H, Ohtsuki S, Hosoya KI, Terasaki T. GAT2/BGT-1 as a system responsible for the transport of gamma-aminobutyric acid at the mouse blood-brain barrier. J Cereb Blood Flow Metab. 2001;21(10):1232-9.

86. Janik R, Thomason LA, Stanisz AM, Forsythe P, Bienenstock J, Stanisz GJ. Magnetic resonance spectroscopy reveals oral Lactobacillus promotion of increases in brain GABA, $N$-acetyl aspartate and glutamate. Neuroimage [Internet]. Elsevier B.V.; 2015;125:988-95. doi:10.1016/j.neuroimage.2015.11.018.

87. Asano Y, Hiramoto T, Nishino R, Aiba Y, Kimura T, Yoshihara $\mathrm{K}$, et al. Critical role of gut microbiota in the production of biologically active, free catecholamines in the gut lumen of mice. Am J Physiol Gastrointest Liver Physiol [Internet]. 
2012;303(11):G1288-95. Available from: http://ajpgi. physiology.org/content/303/11/G1288.abstract.

88. Hernández-Romero D, Sanchez-Amat A, Solano F. A tyrosinase with an abnormally high tyrosine hydroxylase/dopa oxidase ratio: role of the seventh histidine and accessibility to the active site. FEBS J. 2006;273(2):257-70.

89. Kuley E, Balıkcı E, Özoğul I, Gökdogan S, Ozoğul F. Stimulation of cadaverine production by foodborne pathogens in the presence of Lactobacillus, Lactococcus, and Streptococcus spp. J Food Sci [Internet]. 2012;77(12):M650-8. Available from: http://www.ncbi.nlm.nih.gov/pubmed/22853653.

90. Matsumoto M, Kibe R, Ooga T, Aiba Y, Sawaki E, Koga Y, et al. Cerebral low-molecular metabolites influenced by intestinal microbiota: a pilot study. Front Syst Neurosci [Internet]. 2013;7(April):1-19. doi:10.3389/fnsys.2013.00009/abstract.

91. Nishino R, Mikami K, Takahashi H, Tomonaga S, Furuse M, Hiramoto $\mathrm{T}$, et al. Commensal microbiota modulate murine behaviors in a strictly contamination-free environment confirmed by culture-based methods. Neurogastroenterol Motil. 2013;25(6):521-8.

92. Brown RE, Stevens DR, Haas HL. The physiology of brain histamine. Prog Neurobiol. 2001;63(6):637-72.

93. Thomas CM, Hong T, van Pijkeren JP, Hemarajata P, Trinh DV, $\mathrm{Hu} \mathrm{W}$, et al. Histamine derived from probiotic Lactobacillus reuteri suppresses TNF via modulation of PKA and ERK signaling. PLoS One [Internet]. 2012;7(2):e31951. doi:10.1371/ journal.pone.0031951.

94. Handley SA, Dube PH, Miller VL. Histamine signaling through the H(2) receptor in the Peyer's patch is important for controlling Yersinia enterocolitica infection. Proc Natl Acad Sci [Internet]. 2006;103(24):9268-73. Available from: http://eutils. ncbi.nlm.nih.gov/entrez/eutils/elink.fcgi?dbfrom=pubmed\&id= 16717182\&retmode=ref\&cmd=prlinks/npapers $3: / /$ publication/ doi/10.1073/pnas.0510414103.

95. Diebel LN, Liberati DM, Hall-Zimmerman L. H2 blockers decrease gut mucus production and lead to barrier dysfunction in vitro. Surgery [Internet]. Mosby Inc. 2011;150(4):736-43. Available from: http://www.ncbi.nlm.nih.gov/pubmed/22000 186.

96. Mcintosh K, Reed DE, Schneider T, Dang F, Keshteli AH, et al. FODMAPs alter symptoms and the metabolome of patients with IBS: a randomised controlled trial. Gut. 2016. doi:10.1136/ gutjnl-2015-311339.

97. Zhang L, Song J, Hou X. Mast cells and irritable bowel syndrome: from the bench to the bedside. J Neurogastroenterol Motil. 2016;22(2):181-92.

98. Luczynski P, O'Whelan S, O'Sullivan C, Clarke G, Shanahan F, Dinan TG, Cryan JF. Adult microbiota-deficient mice have distinct dendritic morphological changes: differential effects in the amygdala and hippocampus. Eur J Neurosci. 2016; ahead of print.

99. Neufeld KM, Kang N, Bienenstock J, Foster JA. Reduced anxiety-like behavior and central neurochemical change in germ-free mice. Neurogastroenterol Motil [Internet]. 2011;23(3):255-e119. doi:10.1111/j.1365-2982.2010.01620.x.

100. Savignac HM, Corona G, Mills H, Chen L, Spencer JPE, Tzortzis G, et al. Prebiotic feeding elevates central brain derived neurotrophic factor, $N$-methyl-d-aspartate receptor subunits and d-serine. Neurochem Int [Internet]. Elsevier Ltd. 2013;63(8):756-64. Available from: http://linkinghub.elsevier. com/retrieve/pii/S0197018613002623.

101. Bercik P, Verdu EF, Foster JA, Macri J, Potter M, Huang X, et al. Chronic gastrointestinal inflammation induces anxiety-like behavior and alters central nervous system biochemistry in mice. Gastroenterology [Internet]. 2010;139(6):2102-12.e1. Available from: http://linkinghub.elsevier.com/retrieve/pii/S00165085100 10061.

102. Liang S, Wang T, Hu X, Luo J, Li W, Wu X, et al. Administration of Lactobacillus helveticus NS8 improves behavioral, cognitive, and biochemical aberrations caused by chronic restraint stress. Neuroscience [Internet]. 2015;(September). Available from: http://linkinghub.elsevier.com/retrieve/pii/ S0306452215008520.

103. Aguilera M, Cerdà-Cuéllar M, Martínez V. Antibiotic-induced dysbiosis alters host-bacterial interactions and leads to colonic sensory and motor changes in mice. Gut Microbes. 2015;6(1):10-23.

104. Brun P, Gobbo S, Caputi V, Spagnol L, Schirato G, Pasqualin $\mathrm{M}$, et al. Toll like receptor-2 regulates production of glialderived neurotrophic factors in murine intestinal smooth muscle cells. Mol Cell Neurosci [Internet]. Elsevier Inc. 2015;68:24-35. Available from: http://linkinghub.elsevier.com/retrieve/pii/ S1044743115000470.

105. Cryan JF, Dinan TG. Gut microbiota: microbiota and neuroimmune signalling-Metchnikoff to microglia. Nat Rev Gastroenterol Hepatol [Internet]. Nature Publishing Group. 2015;12(9):494-6. doi:10.1038/nrgastro.2015.127.

106. Rea K, Dinan TG, Cryan JF. The microbiome: a key regulator of stress and neuroinflammation. Neurobiol Stress. 2016;. doi:10. 1016/j.ynstr.2016.03.001.

107. Beumer W, Gibney SM, Drexhage RC, Pont-Lezica L, Doorduin J, Klein HC, et al. The immune theory of psychiatric diseases: a key role for activated microglia and circulating monocytes. J Leukoc Biol [Internet]. 2012 [cited 2012 Nov 1];92(September):1-17. Available from: http://www.ncbi.nlm.nih.gov/ pubmed/22875882.

108. Miller AH, Raison CL. The role of inflammation in depression: from evolutionary imperative to modern treatment target. Nat Rev Immunol [Internet]. Nature Publishing Group; 2016;16(1):22-34. Available from: http://www.ncbi.nlm.nih. gov/pubmed/26711676.

109. Tikka T, Fiebich BL, Goldsteins G, Keinanen R, Koistinaho J. Minocycline, a tetracycline derivative, is neuroprotective against excitotoxicity by inhibiting activation and proliferation of microglia. J Neurosci. 2001;21(8):2580-8.

110. Bruce-Keller AJ, Salbaum JM, Luo M, Blanchard E, Taylor $\mathrm{CM}$, Welsh DA, et al. Obese-type gut microbiota induce neurobehavioral changes in the absence of obesity. Biol Psychiatry [Internet]. Elsevier. 2015;77(7):607-15. Available from: http:// linkinghub.elsevier.com/retrieve/pii/S0006322314005204.

111. Hoban AE, Stilling RM, Ryan FJ, Shanahan F, Dinan TG, Claesson MJ, et al. Regulation of prefrontal cortex myelination by the microbiota. Nature Publishing Group. 2016;6(4):e774-9. doi: $10.1038 /$ tp.2016.42.

112. Ochoa-Repáraz J, Mielcarz DW, Wang Y, Begum-Haque S, Dasgupta S, Kasper DL, et al. A polysaccharide from the human commensal Bacteroides fragilis protects against CNS demyelinating disease. Mucosal Immunol. 2010;3(5):487-95.

113. Wang Y, Telesford KM, Ochoa-Repáraz J, Haque-Begum S, Christy M, Kasper EJ, et al. An intestinal commensal symbiosis factor controls neuroinflammation via TLR2-mediated CD39 signalling. Nat Commun [Internet]. 2014;5:4432. Available from: http://www.ncbi.nlm.nih.gov/pubmed/25043484.

114. Lavasani S, Dzhambazov B, Nouri M, Fåk F, Buske S, Molin G, et al. A novel probiotic mixture exerts a therapeutic effect on experimental autoimmune encephalomyelitis mediated by IL-10 producing regulatory $\mathrm{T}$ cells. PLoS One [Internet]. 2010; 5(2):e9009. Available from: http://www.pubmedcentral.nih.gov/ articlerender.fcgi $?$ artid=2814855\&tool=pmcentrez\&rendertype $=$ abstract. 
115. Zunszain PA, Anacker C, Cattaneo A, Carvalho LA, Pariante CM. Glucocorticoids, cytokines and brain abnormalities in depression. Prog Neuropsychopharmacol Biol Psychiatry [Internet]. Elsevier Inc. 2011 [cited 2012 Nov 29];35(3):722-9. Available from: http://www.ncbi.nlm.nih.gov/pubmed/20406 665.

116. Sudo N, Chida Y, Aiba Y, Sonoda J, Oyama N, Yu X-N, et al. Postnatal microbial colonization programs the hypothalamicpituitary-adrenal system for stress response in mice. J Physiol [Internet]. 2004;558(1):263-75. doi:10.1113/jphysiol.2004. 063388.

117. Crumeyrolle-Arias M, Jaglin M, Bruneau A, Vancassel S, Cardona A, Daugé V, et al. Absence of the gut microbiota enhances anxiety-like behavior and neuroendocrine response to acute stress in rats. Psychoneuroendocrinology. 2014;42:207-17.

118. Barouei J, Moussavi M, Hodgson DM. Effect of maternal probiotic intervention on HPA axis, immunity and gut microbiota in a rat model of irritable bowel syndrome. PLoS One [Internet]. 2012;7(10):e46051. Available from: http://www.ncbi.nlm.nih. gov/pmc/articles/PMC3469551/pdf/pone.0046051.pdf.

119. Ait-Belgnaoui A, Durand H, Cartier C, Chaumaz G, Eutamene $\mathrm{H}$, Ferrier L, et al. Prevention of gut leakiness by a probiotic treatment leads to attenuated HPA response to an acute psychological stress in rats. Psychoneuroendocrinology [Internet]. 2012;37(11):1885-95. Available from: http://linkinghub. elsevier.com/retrieve/pii/S0306453012001291.

120. Ait-Belgnaoui A, Colom A, Braniste V, Ramalho L, Marrot A, Cartier C, et al. Probiotic gut effect prevents the chronic psychological stress-induced brain activity abnormality in mice. Neurogastroenterol Motil [Internet]. 2014;26(4):510-20. doi:10. 1111/nmo.12295.

121. Tarr AJ, Galley JD, Fisher SE, Chichlowski M, Berg BM, Bailey MT. The prebiotics $3^{\prime}$ sialyllactose and 6 'sialyllactose diminish stressor-induced anxiety-like behavior and colonic microbiota alterations: evidence for effects on the gut-brain axis. Brain Behav Immun [Internet]. Elsevier Inc. 2015;50:166-77. Available from: http://linkinghub.elsevier.com/retrieve/pii/S088915 9115002342

122. Buffington SA, Viana G, Prisco D, Auchtung TA, Ajami NJ, Petrosino JF, et al. Microbial reconstitution reverses maternal diet-induced social and synaptic deficits in offspring article microbial reconstitution reverses maternal diet-induced social and synaptic deficits in offspring. Cell [Internet]. Elsevier Inc. 2016;165(7):1762-75. doi:10.1016/j.cell.2016.06.001.

123. Tomova A, Husarova V, Lakatosova S, Bakos J, Vlkova B, Babinska K, et al. Gastrointestinal microbiota in children with autism in Slovakia. Physiol Behav [Internet]. Elsevier Inc. 2015;138:179-87. Available from: http://linkinghub.elsevier. com/retrieve/pii/S0031938414005101.

124. Holzer P, Farzi A. Neuropeptides and the microbiota-gut-brain axis. Adv Exp Med Biol [Internet]. 2014;817:39-71. doi:10. 1007/978-1-4939-0897-4.

125. Naseribafrouei A, Hestad K, Avershina E, Sekelja M, Linløkken $A$, Wilson $\mathrm{R}$, et al. Correlation between the human fecal microbiota and depression. Neurogastroenterol Motil [Internet]. 2014;26(8):1155-62. doi:10.1111/nmo.12378.

126. Jiang H, Ling Z, Zhang Y, Mao H, Ma Z, Yin Y, et al. Altered fecal microbiota composition in patients with major depressive disorder. Brain Behav Immun [Internet]. Elsevier Inc. 2015;48:186-94. Available from: http://linkinghub.elsevier. com/retrieve/pii/S0889159115001105.

127. Maes M, Kubera M, Leunis JC, Berk M. Increased IgA and IgM responses against gut commensals in chronic depression: further evidence for increased bacterial translocation or leaky gut. J Affect Disord [Internet]. Elsevier B.V. 2012;141(1):55-62. doi:10.1016/j.jad.2012.02.023.
128. O'Mahony SM, Marchesi JR, Scully P, Codling C, Ceolho A-M, Quigley EMM, et al. Early life stress alters behavior, immunity, and microbiota in rats: implications for irritable bowel syndrome and psychiatric illnesses. Biol Psychiatry [Internet]. Society of Biological Psychiatry. 2009;65(3):263-7. Available from: http:// linkinghub.elsevier.com/retrieve/pii/S0006322308008019.

129. Desbonnet L, Garrett L, Clarke G, Kiely B, Cryan JF, Dinan TG. Effects of the probiotic Bifidobacterium infantis in the maternal separation model of depression. Neuroscience [Internet]. Elsevier Inc. 2010;170(4):1179-88. Available from: http:// linkinghub.elsevier.com/retrieve/pii/S0306452210010729.

130. O'Mahony SM, Hyland NP, Dinan TG, Cryan JF. Maternal separation as a model of brain-gut axis dysfunction. Psychopharmacology (Berl) [Internet]. 2011;214(1):71-88. doi:10. 1007/s00213-010-2010-9.

131. De Palma G, Blennerhassett P, Lu J, Deng Y, Park AJ, Green W, et al. Microbiota and host determinants of behavioural phenotype in maternally separated mice. Nat Commun [Internet]. 2015;6:7735. doi:10.1038/ncomms8735.

132. Bailey MT, Coe CL. The integrity of the intestinal microflora in infant rhesus. Dev Psychobiol. 1999;35:146-55.

133. Harkin A, Kelly JP, Leonard BE. A review of the relevance and validity of olfactory bulbectomy as a model of depression. Clin Neurosci Res. 2003;3:253-62.

134. Park AJ, Collins J, Blennerhassett PA, Ghia JE, Verdu EF, Bercik $\mathrm{P}$, et al. Altered colonic function and microbiota profile in a mouse model of chronic depression. Neurogastroenterol Motil [Internet]. 2013;25(9):733-e575. doi:10.1111/nmo.12153.

135. Dinan TG, Cryan JF. Melancholic microbes: a link between gut microbiota and depression? Neurogastroenterol Motil. 2013;25(9):713-9.

136. Bharwani A, Mian MF, Foster JA, Surette MG, Bienenstock J, Forsythe P. Structural \& functional consequences of chronic psychosocial stress on the microbiome \& host. Psychoneuroendocrinology [Internet]. Elsevier Ltd; 2016;63:217-27. Available from: http://linkinghub.elsevier.com/retrieve/pii/ S0306453015009348.

137. Bailey MT, Dowd SE, Galley JD, Hufnagle AR, Allen RG, Lyte M. Exposure to a social stressor alters the structure of the intestinal microbiota: implications for stressor-induced immunomodulation. Brain Behav Immun [Internet]. Elsevier Inc. 2011;25(3):397-407. Available from: http://linkinghub. elsevier.com/retrieve/pii/S0889159110005295.

138. Philips JGP. The treatment of melancholia by the lactic acid Bacillus. Br J Psychiatry. 1910;56 (234):422-NP. doi:10.1192/ bjp.56.234.422.

139. Steenbergen L, Sellaro R, van Hemert S, Bosch JA, Colzato LS. A randomized controlled trial to test the effect of multispecies probiotics on cognitive reactivity to sad mood. Brain Behav Immun [Internet]. Elsevier Inc. 2015;48:258-64. Available from: http://linkinghub.elsevier.com/retrieve/pii/S08891591150 00884 .

140. Messaoudi M, Lalonde R, Violle N, Javelot H, Desor D, Nejdi A, et al. Assessment of psychotropic-like properties of a probiotic formulation (Lactobacillus helveticus R0052 and Bifdobacterium longum $\mathrm{R} 0175$ ) in rats and human subjects. Br J Nutr. 2011;105(5):755-64

141. Rao AV, Bested AC, Beaulne TM, Katzman MA, Iorio C, Berardi JM, et al. A randomized, double-blind, placebo-controlled pilot study of a probiotic in emotional symptoms of chronic fatigue syndrome. Gut Pathog [Internet]. 2009;1(1):6. Available from: http://www.ncbi.nlm.nih.gov/pubmed/1933 8686.

142. Benton D, Williams C, Brown A. Impact of consuming a milk drink containing a probiotic on mood and cognition. Eur J Clin Nutr. 2007;61(3):355-61. 
143. Liu Y-W, Liu W-H, Wu C-C, Juan Y-C, Wu Y-C, Tsai H-P, et al. Psychotropic effects of Lactobacillus plantarum PS128 in early life-stressed and naïve adult mice. Brain Res [Internet]. Elsevier; 2016;1631:1-12. Available from: http://linkinghub. elsevier.com/retrieve/pii/S0006899315008628.

144. Wang T, Hu X, Liang S, Li W, Wu X, Wang L, et al. Lactobacillus fermentum NS9 restores the antibiotic induced physiological and psychological abnormalities in rats. Benef Microbes [Internet]. 2015;6(5):707-17. doi:10.3920/BM2014.0177.

145. Wei Y, Melas PA, Wegener G, Mathé AA, Lavebratt C. Antidepressant-like effect of sodium butyrate is associated with an increase in TET1 and in 5-hydroxymethylation levels in the Bdnf gene. Int $\mathrm{J}$ Neuropsychopharmacol [Internet]. 2014;18(2):pyu032. Available from: http://ijnp.oxfordjournals. org/content/18/2/pyu032.abstract.

146. Fowler T, Zammit S, Owen MJ, Rasmussen F. A populationbased study of shared genetic variation between premorbid IQ and psychosis among male twin pairs and sibling pairs from Sweden. Arch Gen Psychiatry [Internet]. 2012;69(5):460-6. Available from: http://archpsyc.jamanetwork.com/article. aspx? articleid $=1151484$.

147. Gershon ES, Alliey-Rodriguez N, Liu C. After GWAS: searching for genetic risk for schizophrenia and bipolar disorder. Am J Psychiatry. 2011;168(3):253-6.

148. Severance EG, Yolken RH, Eaton WW. Autoimmune diseases, gastrointestinal disorders and the microbiome in schizophrenia: more than a gut feeling. Schizophr Res [Internet]. Elsevier B.V. 2014. doi:10.1016/j.schres.2014.06.027.

149. Severance EG, Prandovszky E, Castiglione J, Yolken RH. Gastroenterology issues in schizophrenia: why the gut matters. Curr Psychiatry Rep. 2015;17(5):1-10.

150. Diaz R, Wang S, Anuar F, Qian Y, Björkholm B, Samuelsson A. Normal gut microbiota modulates brain development and behavior. 2011;108(7):1-6.

151. Borre YE, O'Keeffe GW, Clarke G, Stanton C, Dinan TG, Cryan JF. Microbiota and neurodevelopmental windows: implications for brain disorders. Trends Mol Med [Internet]. Elsevier Ltd. 2014;20(9):509-18. Available from: http:// linkinghub.elsevier.com/retrieve/pii/S1471491414000811.

152. Biasucci G, Rubini M, Riboni S, Morelli L, Bessi E, Retetangos C. Mode of delivery affects the bacterial community in the newborn gut. Early Hum Dev [Internet]. Elsevier Ltd. 2010;86(Suppl. 1):13-5. doi:10.1016/j.earlhumdev.2010.01.004.

153. Liu D, Yu J, Li L, Ai Q, Feng J, Song C, et al. Bacterial community structure associated with elective cesarean section versus vaginal delivery in chinese newborns. J Pediatr Gastroenterol Nutr [Internet]. 2015;60(2):240-6. Available from: http://www.ncbi.nlm.nih.gov/pubmed/25625578.

154. O’Neill SM, Curran EA, Dalman C, Kenny LC, Kearney PM, Clarke G, et al. Birth by caesarean section and the risk of adult psychosis: a population-based cohort study. Schizophr Bull. 2016;42(3):633-41. doi:10.1093/schbul/sbv152.

155. Shaw W. Increased urinary excretion of a 3-(3-hydroxyphenyl)3-hydroxypropionic acid (HPHPA), an abnormal phenylalanine metabolite of Clostridia spp. in the gastrointestinal tract, in urine samples from patients with autism and schizophrenia. Nutr Neurosci. 2010;13(3):135-43.

156. Bhadra R, Cobb DA, Weiss LM, Khan IA. Psychiatric disorders in toxoplasma seropositive patients-the CD8 connection. Schizophr Bull. 2013;39(3):485-9.

157. Fond G, Macgregor A, Tamouza R, Hamdani N, Meary A, Leboyer $\mathrm{M}$, et al. Comparative analysis of anti-toxoplasmic activity of antipsychotic drugs and valproate. Eur Arch Psychiatry Clin Neurosci. 2014;264(2):179-83.

158. Heimesaat MM, Bereswill S, Fischer A, Fuchs D, Struck D, Niebergall J, et al. Gram-negative bacteria aggravate murine small intestinal Th1-type immunopathology following oral infection with Toxoplasma gondii. J Immunol [Internet]. 2006;177(12):8785-95. Available from: http://www.jimmunol. org/content/177/12/8785.full.

159. Hand TW, Santos LM Dos, Bouladoux N, Molloy MJ, Pagán AJ, Pepper M, et al. Acute gastrointestinal infection induces long-lived microbiota-specific $\mathrm{T}$ cell responses. Science. 2012;337(September):1553-7 (80-).

160. Yolken RH, Severance EG, Sabunciyan S, Gressitt KL, Chen O, Stallings $\mathrm{C}$, et al. Metagenomic sequencing indicates that the oropharyngeal phageome of individuals with schizophrenia differs from that of controls. Schizophr Bull. 2015;41(5):1153-61.

161. Selle K, Klaenhammer TR. Genomic and phenotypic evidence for probiotic influences of Lactobacillus gasseri on human health. Fed Eur Microbiol Soc. 2013;37:915-35.

162. Schoepf D, Hardeep U, Potluri R, Heun R. Physical comorbidity and its relevance on mortality in schizophrenia: a naturalistic 12-year follow-up in general hospital admissions. Eur Arch Psychiatry Clin Neurosci. 2014;264:3-28.

163. Albaugh VL, Judson JG, She P, Lang CH, Maresca KP, Joyal $\mathrm{JL}$, et al. Olanzapine promotes fat accumulation in male rats by decreasing physical activity, repartitioning energy and increasing adipose tissue lipogenesis while impairing lipolysis. Mol Psychiatry [Internet]. Nature Publishing Group. 2011;16(5): 569-81. Available from: http://www.pubmedcentral.nih.gov/ articlerender.fcgi $?$ artid $=2892549 \&$ tool $=$ pmcentrez\&rendertype $=$ abstract.

164. Bäckhed F, Ding H, Wang T, Hooper LV, Koh GY, Nagy A, et al. The gut microbiota as an environmental factor that regulates fat storage. Proc Natl Acad Sci. 2004;101(44):15718-23.

165. Bäckhed F, Manchester JK, Semenkovich CF, Gordon JI. Mechanisms underlying the resistance to diet-induced obesity in germ-free mice. Proc Natl Acad Sci. 2007;104(3):979-84.

166. Nieuwdorp M, Gilijamse PW, Pai N, Kaplan LM. Role of the microbiome in energy regulation and metabolism. Gastroenterology. Elsevier, Inc. 2014;146(6):1525-33.

167. Davey KJ, O'Mahony SM, Schellekens H, O’Sullivan O, Bienenstock J, Cotter PD, et al. Gender-dependent consequences of chronic olanzapine in the rat: effects on body weight, inflammatory, metabolic and microbiota parameters. Psychopharmacology. 2012;221(1):155-69.

168. Davey KJ, Cotter PD, O'Sullivan O, Crispie F, Dinan TG, Cryan $\mathrm{JF}$, et al. Antipsychotics and the gut microbiome: olanzapineinduced metabolic dysfunction is attenuated by antibiotic administration in the rat. Transl Psychiatry [Internet]. 2013;3(August):e309. Available from: http://www. pubmedcentral.nih.gov/articlerender.fcgi?artid=3818006\&tool= pmcentrez\&rendertype $=$ abstract.

169. Haack S, Seeringer A, Thürmann PA, Becker T, Kirchheiner J. Sex-specific differences in side effects of psychotropic drugs: genes or gender? Pharmacogenomics. 2009;10(9):1511-26.

170. Coury DL, Ashwood P, Fasano A, Fuchs G, Geraghty M, Kaul A, et al. Gastrointestinal conditions in children with autism spectrum disorder: developing a research agenda. Pediatrics [Internet]. 2012;130(Supplement):S160-8. Available from: http://pediatrics.aappublications.org/cgi/doi/10.1542/peds.2012$0900 \mathrm{~N}$.

171. Finegold SM, Downes J, Summanen PH. Microbiology of regressive autism. Anaerobe [Internet]. Elsevier Ltd. 2012;18(2):260-2. Available from: http://linkinghub.elsevier. com/retrieve/pii/S1075996411002423.

172. Wang L, Conlon MA, Christophersen CT, Sorich MJ, Angley MT. Gastrointestinal microbiota and metabolite biomarkers in children with autism spectrum disorders. Biomark Med [Internet]. 2014;8(3):331-44. Available from: http://www.ncbi.nlm. nih.gov/pubmed/24712423. 
173. Finegold SM, Dowd SE, Gontcharova V, Liu C, Henley KE, Wolcott RD, et al. Pyrosequencing study of fecal microflora of autistic and control children. Anaerobe [Internet]. Elsevier Ltd. 2010;16(4):444-53. Available from: http://linkinghub.elsevier. com/retrieve/pii/S1075996410001010.

174. Parracho HM. Differences between the gut microflora of children with autistic spectrum disorders and that of healthy children. J Med Microbiol [Internet]. 2005;54(10):987-91. doi:10. 1099/jmm.0.46101-0.

175. Sandler RH, Finegold SM, Bolte ER, Buchanan CP, Maxwell $\mathrm{AP}$, Väisänen ML, et al. Short-term benefit from oral vancomycin treatment of regressive-onset autism. J Child Neurol. 2000;15(7):429-35.

176. Wang L, Christophersen CT, Sorich MJ, Gerber JP, Angley MT, Conlon MA. Elevated fecal short chain fatty acid and ammonia concentrations in children with autism spectrum disorder. Dig Dis Sci. 2012;57(8):2096-102.

177. de Theije CGM, Wopereis H, Ramadan M, van Eijndthoven T, Lambert J, Knol J, et al. Altered gut microbiota and activity in a murine model of autism spectrum disorders. Brain Behav Immun [Internet]. Elsevier Inc. 2014;37:197-206. Available from: http://linkinghub.elsevier.com/retrieve/pii/S088915911 3005904.

178. de Theije CGM, Koelink PJ, Korte-Bouws GAH, Lopes da Silva $\mathrm{S}$, Korte SM, Olivier B, et al. Intestinal inflammation in a murine model of autism spectrum disorders. Brain Behav Immun [Internet]. Elsevier Inc. 2014;37:240-7. Available from: http://linkinghub.elsevier.com/retrieve/pii/S0889159113005898.

179. Schwartzer JJ, Careaga M, Onore CE, Rushakoff JA, Berman RF, Ashwood P. Maternal immune activation and strain specific interactions in the development of autism-like behaviors in mice. Transl Psychiatry [Internet]. Nature Publishing Group. 2013;3(3):e240. Available from: http://www.pubmedcentral.nih. gov/articlerender.fcgi? $\operatorname{artid}=3625915 \&$ tool $=$ pmcentrez\&render type $=$ abstract.

180. Machado CJ, Whitaker AM, Smith SEP, Patterson PH, Bauman MD. Maternal immune activation in nonhuman primates alters social attention in juvenile offspring. Biol Psychiatry [Internet]. Elsevier. 2015;77(9):823-32. Available from: http://linkinghub. elsevier.com/retrieve/pii/S000632231400643X.

181. Atladóttir HÓ, Thorsen P, Østergaard L, Schendel DE, Lemcke $\mathrm{S}$, Abdallah $\mathrm{M}$, et al. Maternal infection requiring hospitalization during pregnancy and autism spectrum disorders. J Autism Dev Disord. 2010;40(12):1423-30.

182. Hsiao EY, McBride SW, Hsien S, Sharon G, Hyde ER, McCue $\mathrm{T}$, et al. Microbiota modulate behavioral and physiological abnormalities associated with neurodevelopmental disorders. Cell [Internet]. Elsevier Inc. 2013;155(7):1451-63. Available from: http://linkinghub.elsevier.com/retrieve/pii/S0092867413 014736.

183. Thomas RH, Meeking MM, Mepham JR, Tichenoff L, Possmayer F, Liu S, et al. The enteric bacterial metabolite propionic acid alters brain and plasma phospholipid molecular species: further development of a rodent model of autism spectrum disorders. J Neuroinflamm. 2012;9(1):153.

184. Foley KA, MacFabe DF, Kavaliers M, Ossenkopp K-P. Sexually dimorphic effects of prenatal exposure to lipopolysaccharide, and prenatal and postnatal exposure to propionic acid, on acoustic startle response and prepulse inhibition in adolescent rats: relevance to autism spectrum disorders. Behav Brain Res [Internet]. Elsevier B.V. 2015;278:244-56. Available from: http://linkinghub.elsevier.com/retrieve/pii/S0166432814006305.

185. MacFabe DF. Enteric short-chain fatty acids: microbial messengers of metabolism, mitochondria, and mind: implications in autism spectrum disorders. Microb Ecol Health Dis [Internet]. 2015;26:28177. Available from: http://www.ncbi.nlm.nih.gov/ pubmed/26031685.

186. White SW, Oswald D, Ollendick T, Scahill L. Anxiety in children and adolescents with autism spectrum disorders. Clin Psychol Rev [Internet]. Elsevier Ltd. 2009;29(3):216-29. Available from: http://linkinghub.elsevier.com/retrieve/pii/ S027273580900004X.

187. Mayer EA, Padua D, Tillisch K. Altered brain-gut axis in autism: comorbidity or causative mechanisms? BioEssays [Internet]. 2014;36(10):933-9. doi:10.1002/bies.201400075.

188. Son JS, Zheng LJ, Rowehl LM, Tian X, Zhang Y, Zhu W, et al. Comparison of fecal microbiota in children with autism spectrum disorders and neurotypical siblings in the simons simplex collection. PLoS One. 2015;10(10):1-19.

189. Parracho HMRT, Gibson GR, Knott F, Bosscher D, Kleerebezem M, McCartney AL. A double-blind, placebo-controlled, crossover-designed probiotic feeding study in children diagnosed with autistic spectrum disorders. Int J Probiotics Prebiotics. 2010;5(2):69-74.

190. Kałuzna-Czaplińska J, Błaszczyk S. The level of arabinitol in autistic children after probiotic therapy. Nutrition. 2012;28(2):124-6.

191. Dinan TG, Cryan JF. Mood by microbe: towards clinical translation. Genome Med [Internet]. Genome Med. 2016;36-8. doi:10.1186/s13073-016-0292-1. 